IZA DP No. 4814

Economic Mobility, Family Background, and the Well-Being of Children in the United States and Canada

Miles Corak

Lori Curtis

Shelley Phipps

March 2010 


\title{
Economic Mobility, Family Background, and the Well-Being of Children in the United States and Canada
}

\author{
Miles Corak \\ University of Ottawa, \\ CReAM and IZA \\ Lori Curtis \\ University of Waterloo \\ Shelley Phipps \\ Dalhousie University
}

\author{
Discussion Paper No. 4814 \\ March 2010
}

IZA

P.O. Box 7240

53072 Bonn

Germany

Phone: +49-228-3894-0

Fax: +49-228-3894-180

E-mail: iza@iza.org

\begin{abstract}
Any opinions expressed here are those of the author(s) and not those of IZA. Research published in this series may include views on policy, but the institute itself takes no institutional policy positions.

The Institute for the Study of Labor (IZA) in Bonn is a local and virtual international research center and a place of communication between science, politics and business. IZA is an independent nonprofit organization supported by Deutsche Post Foundation. The center is associated with the University of Bonn and offers a stimulating research environment through its international network, workshops and conferences, data service, project support, research visits and doctoral program. IZA engages in (i) original and internationally competitive research in all fields of labor economics, (ii) development of policy concepts, and (iii) dissemination of research results and concepts to the interested public.
\end{abstract}

IZA Discussion Papers often represent preliminary work and are circulated to encourage discussion. Citation of such a paper should account for its provisional character. A revised version may be available directly from the author. 


\section{ABSTRACT}

\section{Economic Mobility, Family Background, and the Well-Being of Children in the United States and Canada*}

This comparative study of the relationship between family economic background and adult outcomes in the United States and Canada addresses three questions. First, is there something to explain? We suggest that the existing literature finds that there are significant differences in the degree of intergenerational economic mobility between these two countries, relative mobility being lower in the United States. This is the result of lower mobility at the very top and the very bottom of the earnings distribution. Second, does this reflect different underlying values of the citizens in these countries? Findings from comparable public opinion polls suggest that this is not the case. The citizens of both countries have a similar understanding of a successful life, one that is rooted in individual aspirations and freedom. They also have similar views on how these goals should be attained, but with one important exception: Americans differ in that they are more likely to see the State hindering rather than helping the attainment of these goals. Finally, how do the investments these countries make in the future of their children through the family, the labour market, and public policy actually differ? Using a number of representative household surveys we find that the configuration of all three sources of investment and support for children differs significantly, disadvantaged American children living in much more challenging circumstances, and the role of public policy not as strong in determining outcomes.

JEL Classification: J62, J13, I3

Keywords: $\quad$ intergenerational mobility, children, Canada, United States

Corresponding author:

Miles Corak

Graduate School of Public and International Affairs

University of Ottawa

Desmarais Building, Room 11156

55 Laurier Avenue East

Ottawa, Ontario K1N 6N5

Canada

E-mail: corak@iza.org

\footnotetext{
* This research was supported financially by the PEW Charitable Trusts and the Social Sciences Humanities Research Council of Canada through a Standard Research Grant to Corak. EKOS Research Associates conducted the public opinion poll of economic mobility in Canada, and the help of Frank Graves and Angela Scanlon of EKOS is acknowledged with thanks. Some of these findings have been released as Corak (2010), and are used here with permission from the Pew Charitable Trust. The support of the Statistics Canada Halifax Research Data Centre which facilitated access to some of the Canadian surveys used in the analysis, and the research assistance of Stephanie Andrews, Ali Akba Ganghro, and Lynn Lethbridge is also gratefully acknowledged. The paper also benefited from the comments and suggestions of participants, particularly those of Julia Issacs, at the working conference on "Intergenerational Mobility within and across Nations" sponsored in part by the Russell Sage Foundation and organized by the Institute for Research on Poverty at the University of Wisconsin-Madison in September 2009.
} 


\section{NON-TECHNICAL SUMMARY}

In the United States there is a long social science tradition recognizing the value of a federal structure in developing effective public policies. Significant variations in public programs across States offers opportunities for learning about what works and what doesn't, and hence for the refinement of policy goals and improvements in program implementation. Our comparative study of the relationship between family economic background and adult outcomes in the United States and Canada is offered in this spirit, by extending the scope of the comparison across countries it offers another dimension for understanding the nature of social goals, and how different institutional contexts play out in attaining them.

There are important similarities and differences between these two countries. The starting point for our analysis is the difference in outcomes that has been observed in the empirical economics literature dealing with economic mobility across the generations. International comparisons of the average degree of generational earnings mobility suggest that Canada is more mobile than the United States, but a closer look at studies that use particularly high quality data that are directly comparable across this pair of countries suggests that the difference is even larger than implied by the broad international literature. On average Canada is up to three times more mobile than the United States. Or another way of putting it, up to three times as much inequality is passed across the generations in the United States than in Canada. Furthermore, these differences arise from differences in the extremes of the earnings distribution: there is notably less mobility at the very top and the very bottom of the American income ladder. For this reason we focus our more detailed comparative analysis not just on the average child but also on the relatively disadvantaged, and try to chart the prospects for upward mobility in these two countries.

These cross-country differences in outcomes are not a reflection of different societal preferences, or interpretations of the meaning of equality of opportunity. In fact, it is valuable to compare these two particular relatively rich countries because they are so much alike. This similarity in public attitudes is confirmed in the comparative public opinion polls conducted and reported upon. Both countries value the ideal of equality of opportunity, and both define it in terms of individual freedoms but also individual responsibilities. Americans, however, are more inclined to view government as doing more to hinder than help this process. Yet, at the same time the citizens of both countries recognize the need for public policy to contribute to reaching this ideal, with Americans believing more than Canadians that a whole host of interventions would be effective in improving the prospects for economic mobility. One interpretation of these findings - an interpretation that only becomes evident in a comparative context - is that in some sense this need is going unmet in the United States.

This is reflected in the actual resources available to children. We offer a descriptive overview of these resources organized loosely around a model of intergenerational economic mobility that highlights the role of families, labour markets, and public policies as together determining the degree of mobility and explaining differences between jurisdictions. The family context in which children are raised in the United States is more challenging than in Canada, raising the risks that some children will not see the full development of their capabilities. American labour markets are also more unequal raising the stakes for child outcomes, both elevating opportunities and heightening risks. Finally, public policy is less "progressive," not compensating in the same degree for family background and labour market inequality.

The portrait we paint of young children across these three dimensions underscores the fact that childhood outcomes differ for children before they reach their teen years, and potentially set them down pathways that will lead to different adult outcomes. Mental and physical health, school readiness, and some education outcomes are all more developed in Canada. But this portrait also highlights some particularly relevant institutional differences in public policy between the countries that merit closer attention as the underlying causes. 
The first concerns health care. The universal provision of accessible health care in Canada plays a role in the preventative care of children, reducing the number and severity of health shocks that could potentially lead to more severe difficulties. But in both countries issues of access are also more subtle, associated with economic and social barriers limiting visits to health care providers, ability to pay for prescriptions, and knowledge as to how to navigate the health care system. The anecdotal evidence provided by Scott (2005) with respect to the ability of adults to access and respond to care providers in the United States probably rings true for children on both sides of the border.

The second concerns the flexibility that parents have in making child care choices and deciding upon hours of work. The two countries have very different policies that offer different opportunities for parents in balancing the demands of family and workplace, particularly in the early years of a child's life. Canadian mothers and fathers would appear to have more flexibility as a result of significant policy changes in the mid 1990s that extended paid leave during the year after a child's birth as well as the legislative right to return to their jobs. There seems also to be more use of part-time employment. In the United States the limited nature of parental leave leads to a polarization in family decisions, with relatively well-off families able to either afford private child care or to have the mother withdraw from the labour market, while at the other extreme lone mothers have fewer options and are much more likely to continue working. This discussion leaves aside important issues of the quality of the care arrangements, an area of continued research.

The third deals with labour market inequalities and the role of tax-transfer programs. Left to their own, labour markets lead to roughly the same level of income poverty in these two countries, though there is more affluence on average in the United States and greater inequality. While the average Canadian child is not as affluent as the average American, the poorest Canadian is not as poor in an absolute sense as Americans at the bottom of the income distribution. Public income transfers play a much more important role in reducing poverty among Canadian children with virtually all families receiving some measure of public support. This is likely the result of the Canadian Child Tax Benefit, a progressive system of income transfers delivered through the income tax system with the generosity of the benefit varying with family market income and number of children. While this program has played a limited role in reducing the incidence of low income, it has significantly reduced the severity of poverty. This design contrasts with the Employment Income Tax Benefit in the United States, which is tied to employment. All this said our analysis has not accounted for the role of in-kind transfers in the United States, nor analysed the relative merits of targeted in-kind support versus broad-based money transfers. These alternative delivery mechanisms need to be evaluated not only in terms of the level of support they offer, but once again with respect to more subtle issues of access, stigma, and take-up rates.

Finally, our analysis highlights but leaves unaddressed important details concerning the quality and the variation in quality of public schooling. As suggested the financing of public education is very different across these countries. Education is a provincial responsibility in Canada, much in the way that the States have primary responsibility in the United States. But the financial resources available to schools are not linked to local property taxes, being tied rather to the province-wide income tax. This permits a more equal allocation of resources across municipalities and neighbourhoods than the United States, and may contribute to a higher overall level of quality that is ultimately reflected in the higher test score outcomes we document for Canadian children just before their entry to high school.

It is important to re-emphasize that much of our analysis refers to a particular cohort of young people, those who were young teens at the turn of the century and who will soon be coming of age as adults. Demographics, labour markets, and public policy have all changed significantly over the course of the last decade. These changes may have a bearing on how younger cohorts of children will fare as adults. But given the configuration of these forces during the period relevant for the cohort we study, essentially the 1990s and early 2000s, our analysis suggests that the next wave of intergenerational mobility studies - which will be 
based on this very group - will likely find that the degree of mobility continues to remain greater in Canada than in the United States.

All this said, to some measure the observation that Alesina and Glaeser (2004) make in beginning their explanation for the much smaller size of the welfare state in the United States compared to Europe also holds when the comparison is made to Canada: "If one were born (and remained) at the bottom end of the income distribution, one would be much better taken care of by government policies in Europe than by those in the United States." (Alesina and Glaeser 2004, page 2.) But their explanation for different levels of government support is not so easily transposed to the Canadian context. "American institutions [they argue] have strengthened the political right and given anti-redistribution politicians the ability to push their world view - and this world view emphasizes economic opportunity. European institutions, to the contrary, have empowered the left; as a result, leftist leaders have been able to indoctrinate Europeans with Marxist ideals about class solidarity and the capriciousness of the capitalist system." (page 12.)

This sharp dichotomy between values and institutions that pit equality of opportunity against equality of outcomes does not resonate in a comparison involving the United States and Canada. Our analysis has shown that Canadians value equality of opportunity no more and no less than Americans, and they have as much aversion for equality of outcomes. But Canadians have drawn the balance between family and labour markets differently than Americans - using in a pragmatic way the instruments available through public policy - and for this reason the tie between family background and the adult outcomes of children will likely to continue to be looser in Canada for at least another generation. 


\section{Introduction}

The United States and Canada share a good deal in common, making them arguably the two most similar countries in the OECD. Not least of these similarities is a common perspective that informs and defines the self-image and social goals of their citizens, whose histories and cultures have been shaped by newcomers seeking opportunities and better lives. The idea of "equality of opportunity" in which inherited aspects of family background play a second role to individual motivation, talents, and energy in determining economic success is an important part of this common heritage, and makes "land of opportunity" a common defining metaphor.

Yet there are very important differences in economic outcomes on the two sides of the 49th parallel. The United States is richer, with a per capita income in 2007 that is almost 20 percent higher than in Canada (OECD 2009). But it is also more unequal. In the United States households ranking at the top decile of the income distribution have almost six times as much as those at the bottom decile, a ratio that is the third highest among 30 OECD countries. In Canada this ratio is just over four, essentially at the OECD average and 18th among the 30 countries (OECD 2008, Table 1.A2.2, page 51).

The research literature directed to an understanding of these similarities and differences has a long history, with a notable starting point being the work of Seymour Martin Lipset who studied the much stronger tendency for collective action in Canada, and attempted to understand the rise of "agrarian socialism" as offering support for social democratic political parties, parties that were and continue to be absent in the United States (Lipset 1950). This established political-sociology literature extends through the work of EspingAndersen (1990), Alesina and Glaeser (2004) and others. But there have also been numerous studies on social and economic outcomes, with perhaps the most comprehensive collected in an edited volume under the title Small Differences that Matter (Card and Freeman 1993).

Our research addresses one difference that has been uncovered since the publication of this book in the early 1990s, that economic mobility across the generations - the tie between family economic background and the adult attainments of children - is not the same between these countries. This fact has drawn a certain amount of attention as it informs public policy concerns about equality of opportunity, the functioning of the labour market, as well as policies dealing with education, health care, immigration, and support to families with children (Haskins and Sawhill 2009, New York Times 2005, Sawhill and Morton 2008, Wessel 2005).

A general consensus has developed in the applied economics literature that relative mobility of earnings across the generations is greater in Canada than in the United States. On average, Americans are much more likely to occupy the same place in the earnings distribution as their parents than Canadians. The most common indicator of the degree to which relative inequality is passed on across the generations is the intergenerational earnings elasticity between fathers and sons: the percentage change in a child's adult earnings for each 
percentage change in the father's permanent earnings. This has been measured to be about 0.4 to as high as 0.6 in the United States in the most recent wave of research since the influential work of Solon (1992) and Zimmerman (1992). In Canada, this same measure is often cited as being less than half as great, in the neighbourhood of 0.2 or so, implying that less than one-fifth of an earnings advantage is passed on across the generations compared to about one-half or more in the United States.

Our analysis takes these overall average indicators of the degree of stickiness between family background and the adult economic outcomes of children as its starting point. One way of appreciating the underlying reasons for any particular level of generational mobility in a country is to focus on changes over time, as for example in Aaronson and Mazumder (2008), Lee and Solon (2009), Mayer and Lopoo (2004), Mulligan (1997), and Reville (1995) for the United States, and Fortin and Lefebvre (1998) in Canada. But another way is to focus on changes across space, that is, on cross-country differences. Our research method is predicated on the idea that the Canada-US comparison is an analytically valuable one to make because of the degree of similarity in many features of these societies, and because of the availability of relatively comparable data. As such a cross-country comparison can complement analyses across time within countries in not only highlighting differences between the countries, but also possible causal mechanisms and particularly the role of public policy in determining the overall degree of generational mobility within a country.

The research summarized in this chapter proceeds by addressing three questions. Is there something to explain? If there is, does it reflect differences in values and the meaning of the social goals they underlie? And finally, if values associated with the meaning of equality of opportunity are the same, then are there differences in the investments made in children that could account for the different outcomes?

We summarize and document the findings in the existing literature that there are significant differences in the degree of intergenerational economic mobility between these two countries, with the United States characterized by a significantly lower average degree of relative mobility. Our review suggests that these differences are not due to differences in measurement, analytical methods, or underlying data instruments. Rather they reflect the fact that family background is more strongly related to the adult outcomes of children-that intergenerational mobility is lower - at the very top and the very bottom of the earnings distribution in the United States.

Findings from comparable public opinion polls suggest that these differences cannot be characterized as being the result of fundamentally different values over the meaning of equality of opportunity, and hence different social choices that in some sense are optimal for each country. The citizens of both countries have a very similar sense of the meaning of a good and successful life, one that is rooted in individual aspirations and freedom. They also have similar views on how these goals should be attained with individual attributes like hard work and human capital accumulation being central. But there is an important exception. Americans differ from Canadians in that they are more likely to see government 
hindering rather than helping the attainment of these goals.

These two countries draw different boundaries between the roles of family, market, and the public sector in investing in the capacities of children. Using a number of representative household surveys we find that the configuration of all three sources of investment and support for children differs significantly, with disadvantaged children living in much more challenging familial circumstances in the United States, with their parents having more difficulty in maintaining a strong foothold in labour markets characterized by greater inequalities, and the role of the welfare state not as strong in determining their outcomes.

\section{Comparable estimates of earnings mobility across the generations}

The empirical framework for the measurement of the degree of intergenerational earnings mobility is in large part informed by the following equation.

$$
Y_{i, t}=\alpha+\beta Y_{i, t-1}+\epsilon_{i, t}
$$

$Y$ represents the outcome of interest, generally earnings or permanent income measured in natural logarithms, $i$ indexes families, and $t$ indexes generations. As such, the adult earnings of a child from a particular family, $Y_{i, t}$, is related to the average earnings of the members of a similar age cohort, $\alpha$, plus a deviation from the average that consists of two parts. The first part reflects the fraction of parental advantage inherited by the child, as indicated by $\beta Y_{i, t-1}$; the second, $\epsilon_{i, t}$ reflects all other influences not correlated with parental earnings.

This is an exercise in description, not causation. The empirical challenge is to obtain an accurate estimate of $\beta$, which represents, when earnings are measured in natural logarithms, the intergenerational elasticity of earnings. This is an overall average indicator of the degree to which inequality is transmitted across the generations, and as such might be an interesting statistic to describe an economy, much in the way that the Gini coefficient is used to summarize inequality at a point in time.

The intergenerational elasticity, however, is more challenging to estimate than the Gini coefficient, the ideal data being developed from a longitudinal study of a large, nationally representative sample of individuals and families. These individuals and families must be followed for a period long enough to obtain a credible estimate of the permanent income available to the parents while the child is growing up, and long enough to observe the child in adulthood at a roughly similar stage in the life cycle as his or parents. In practice the nature of the data available across countries differs, and therefore the extent to which measurement errors associated with the calculation of permanent income will also differ, as will the representativeness and size of the available sample. Corak (2006) points out that a comprehensive reading of the available empirical

literature would not lead to any substantive conclusions about the relative size of $\beta$ across countries if no account were taken of how the measurement and life cycle 
Figure 1: Comparable estimates of the intergenerational elasticity of earnings between fathers and sons for selected rich countries

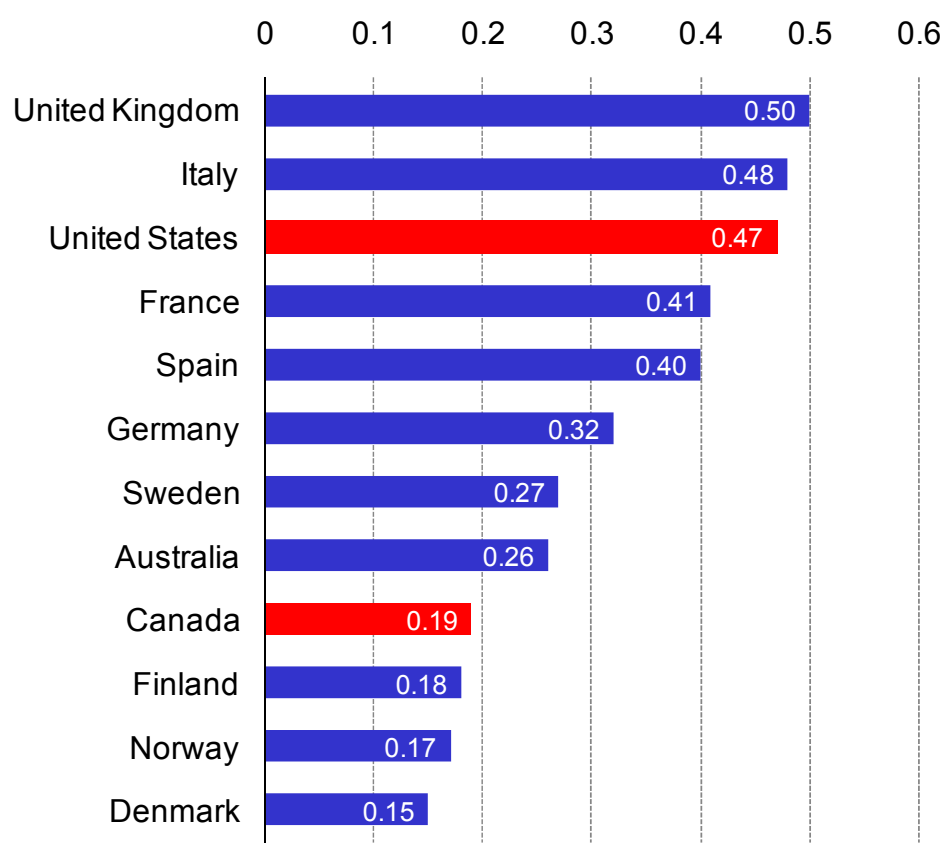

Source: Adapted and updated with information for Italy, Spain and Australia from Corak (2006), Table 1 and Piraino (2007), Cervini (2009), and Leigh (2007).

errors outlined by Solon (1992), Zimmerman (1992), Grawe (2006), and Haider and Solon (2006) are addressed. Not all studies are created equal in this regard, and the derivation of robust and comparable estimates of the intergenerational elasticity must take this into account before drawing any conclusions.

A set of international comparable estimates drawn from this literature that recognizes differences in study designs is offered in Figure 1. These estimates are not meant as definitive for each country, but rather as the best estimates suitable for international comparisons. Further, they refer exclusively to the elasticity between father and son earnings, the literature on both parents and on daughters still being too sparse. The United States is among the least mobile countries in this group; Canada among the most mobile. The meta analysis of the literature upon which these findings are based could reasonably suggest a range of estimates for the United States of between 0.40 at the low end to 0.52 at the upper end. But this still is outside a comparable set of bounds for Canada, which range from 0.16 to 0.21 (Corak 2006, Table 1, page 152).

A more definitive estimate of the intergenerational elasticity in father-son 
earnings for the United States is offered by Mazumder (2005, 2004). There are many studies estimating this statistic, and the very strong majority are based on the Panel Study of Income Dynamics (PSID). Indeed, to some important degree the rebirth of this empirical literature in the early 1990s was due to the availability of sufficiently long panels of information in this data set. But the drawback is that only rather small analytical samples can be constructed for intergenerational studies, measuring roughly in the couple of hundreds. Mazumder's research is distinguished by the development of a new data set involving a linkage between survey data and administrative data on earnings. ${ }^{1}$ His analysis of samples that are six to eight times as large as those available through the PSID—roughly 1,300 to 1,600 father-son pairs-coupled with higher quality earnings data for parents that span up to 15 years leads to an estimate of the intergenerational elasticity of earnings between fathers and sons as high as 0.613 , with an associated standard error of 0.096 (Mazumder 2005, Table 7, page 248).

The nature of the data and the age cohorts used in this study make it directly comparable to the Canadian. Corak and Heisz (1999) use administrative data associated with the Canadian income tax system to obtain earnings for a sample of about 340,000 father and son pairs. Using paternal earnings over a five year period they estimate the intergenerational elasticity to be 0.23 with a standard error of 0.003 (Corak and Heisz 1999, Table 3, page 513).

What is striking, however, is that the sample selection rules used in these two studies are very close to being the same. Mazumder $(2005,2004)$ examines a young cohort of men age 15 to 20 in 1983-being born between 1963 and 1968 - and who were living with their parents in that year. These young men were at least 27 years of age when their earnings are measured in 1995 to 1998. Corak and Heisz (1999) examine a cohort of men age 16 to 19 in 1982-being born between 1963 and 1966 - who filed an income tax return while living at home between 1982 and 1986. These young men were at least 27 years of age when their earnings are measured between 1993 and 1995.

On this basis the difference in the degree of relative intergenerational mobility is higher than suggested by Figure 1, being about three times as great in Canada as in the United States. ${ }^{2}$ Just as importantly, however, these two studies are based on sufficiently large sample sizes to permit analyses of differences in mobility at different points in the parental earnings distribution. Both studies present decile transition matrices showing that these large differences

\footnotetext{
${ }^{1}$ He links the Survey of Income and Program Participation to Social Security Administration Summary Earnings Data, offering high quality earnings information on up to 1,600 father and son pairs.

${ }^{2}$ These differences in the intergenerational elasticities are not due to demographic differences associated, for example, with immigration. It is generally recognized that immigration policies have differed for some time, with the United States more likely to accept low-skilled immigrants and with a significant fraction of illegal immigrants while Canada is inclined to select high-skilled immigrants. Studies of the intergenerational mobility of immigrants in both countries have found that the father-son earnings elasticities are no different than for the overall population: ranging from 0.4 to 0.6 in the United States, and essentially 0.2 in Canada. See Card, DiNardo and Estes (2000) and Aydemir, Chen, and Corak (2009).
} 
Figure 2: Earnings deciles of sons born to top decile fathers: Canada and United States

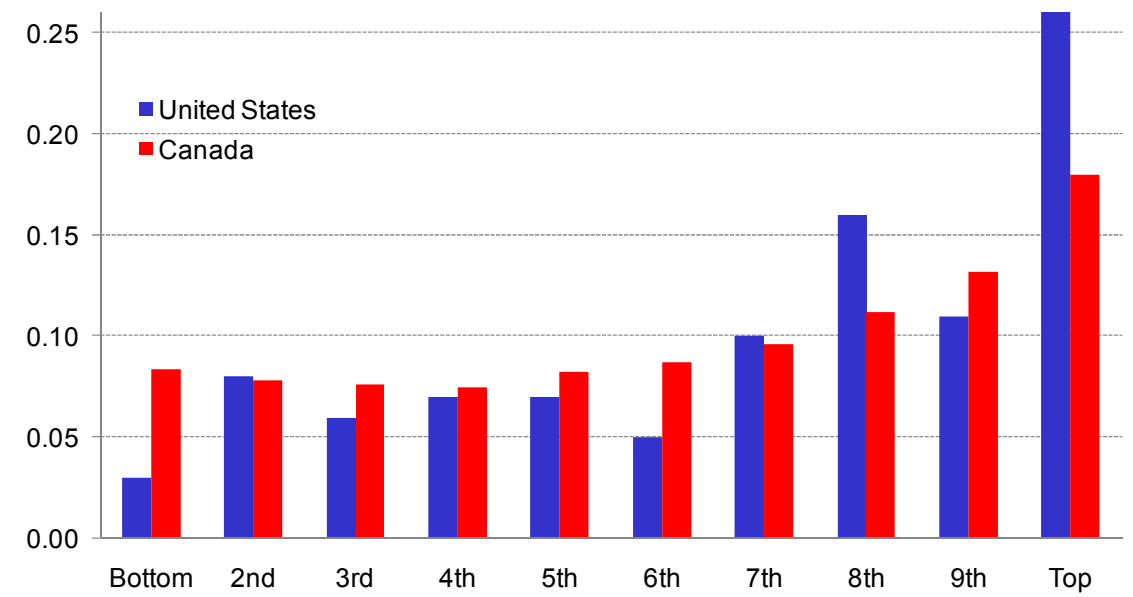

Source: Corak and Heisz (1999), Table 6, page 520; Mazumder (2004), Table 2.2 , page 93 .

Figure 3: Earnings deciles of sons born to bottom decile fathers: Canada and United States

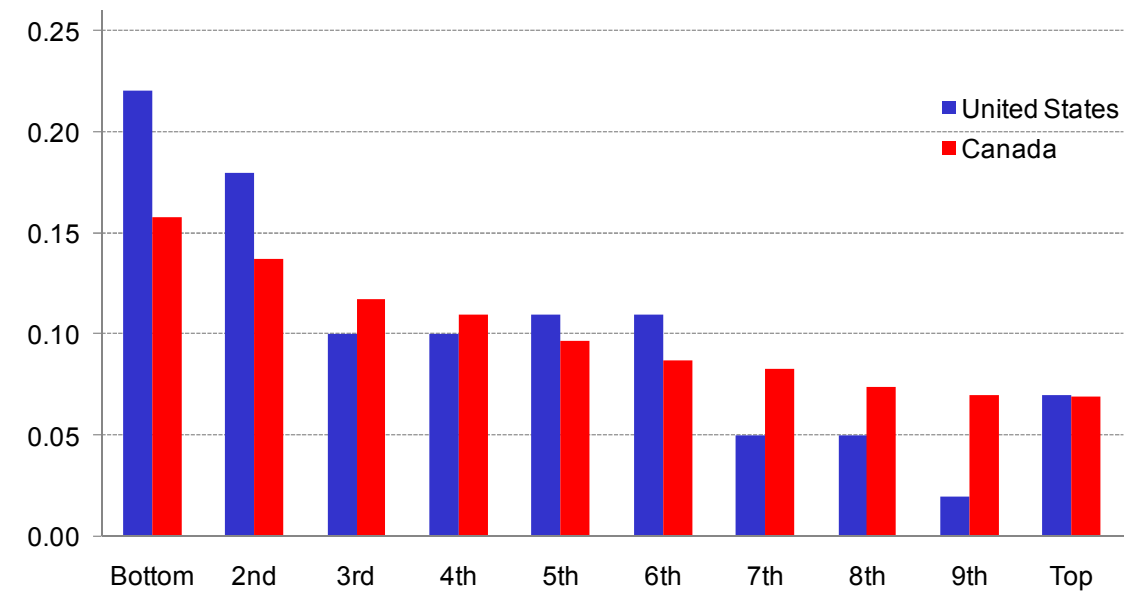

Source: Corak and Heisz (1999), Table 6, page 520; Mazumder (2004), Table 2.2 , page 93 . 
Figure 4: Upward generational earnings mobility in Canada and the United States: Chances that sons raised in the bottom half of the earnings distribution move to the top half

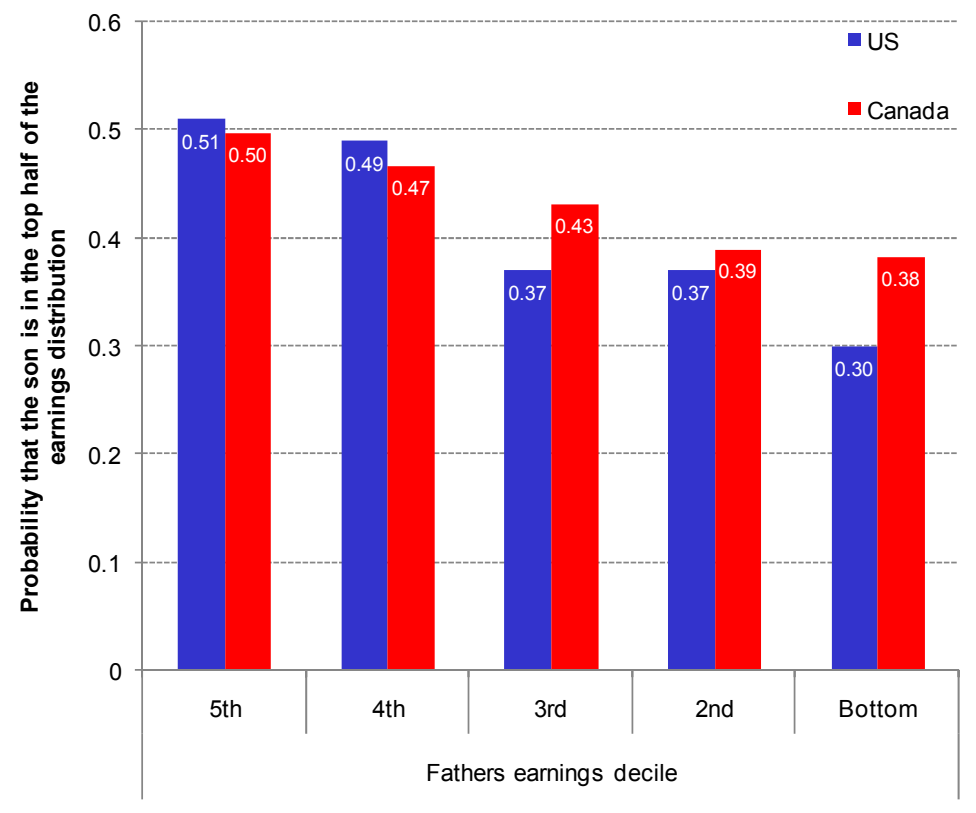

Source: Corak and Heisz (1999), Table 6, page 520; Mazumder (2004), Table 2.2 , page 93 .

in average mobility are due to differences at the extremes of the distribution. These are summarized in Figures 2 and 3 for sons born respectively to top decile and bottom decile fathers.

Of the sons born to fathers whose earnings places them among the top ten percent of earners in their distribution over one-quarter (26 percent) grow up to be adults who are also in the top ten percent of their earnings distribution. It is also notable that these sons are more likely to drop to the very bottom of their earnings distribution in Canada than in the United States, where 8.4 percent find themselves in the bottom compared to just 3 percent. If downward mobility is less likely in the United States, so is upward mobility. Twenty-two percent of sons born to bottom decile American fathers remain in the bottom as adults, and a further 18 percent only move up one decile. In Canada just under 16 percent (15.8) remain in the bottom with 14 percent moving up only one decile. ${ }^{3}$

\footnotetext{
${ }^{3}$ These findings also suggest that Canada has more in common with Denmark, Finland, Norway, and Sweden-countries with arguably the highest levels of social expenditure as a
} 
Figure 4 summarizes the extent of upward mobility in these countries by contrasting the chances that a son born to a father in the bottom half of the earnings distribution will move to the top half. While the chances of this happening for those born to fathers just below the median, in the fourth or fifth deciles, are similar in the two countries - around 50 percent for an upward movement of one or two deciles - they are noticeably higher in Canada at lower deciles. The probability that a bottom decile Canadian son will have adult earnings placing him in the top half of his earnings distribution is 0.38 , but for a comparable American this is 0.30. In fact, a son raised in the bottom decile in Canada has about the same chances of reaching the top half of the earnings distribution as a third decile son in the United States.

\section{Economic mobility and equality of opportunity}

While these differences in generational economic mobility are significant, both in a substantive and a statistical sense, they do not necessarily imply differences in equality of opportunity. Jencks and Tach (2006) and Roemer (2004) address this issue, pointing out in particular that complete equality of opportunity is not indicated by an intergenerational elasticity of zero, or entries in a transition matrix that are all the same. In this sense it is not as if Canada is further along in some optimal sense than the United States. The existing differences could very well be optimal for each country, reflecting underlying values and the social choices that respect them.

Roemer (2004) is particularly clear on this point. At the risk of oversimplifying his argument, he defines equality of opportunity as follows: "Equality of opportunity ... views inequities of outcome as indefensible, ethically speaking, when and only when they are due to differential circumstances." (Roemer 2004, page 50.) The issue, of course is how to define "circumstances." Children resemble their parents for all kinds of reasons, some of which tend to be persistently rewarded in the labour market. To paraphrase Roemer, there are three successively broader fields, or circumstances, that would give rise to successively broader definitions of equality of opportunity and hence state intervention.

At one extreme is the influence of social connections and family income in facilitating access to important resources that influence capabilities and the chances children succeed. Roemer suggests that most citizens in the rich countries might agree with the notion that equality of opportunity would be promoted if the influence of inherited wealth, connections, and outright nepotism in determining access to health care, education and jobs were eliminated.

percent of GDP in the OECD-than they with the United States. In comparing the United States to the United Kingdom and these Nordic countries Jantti et al. (2006, page 2) observe that "what distinguishes the pattern of male intergenerational mobility in the U.S. ... is the low upwards mobility for sons from low income families in the United States." Their results are based on quintile transition matrices, and though not directly comparable to the findings summarized above, are roughly of the same magnitude for the Nordic countries as for Canada. See their table 12, page 33 . 
He also suggests, at the other extreme, that most citizens would disagree with the suggestion that the influence of inherited ability should be eliminated in order to promote equality of opportunity. It is notable, after all, that even the most mobile countries listed in Figure 1 have not completely eliminated the intergenerational link in earnings.

But between these extremes societies may legitimately make different choices concerning the extent to which parent-child correlations in outcomes are in accord with a level playing field. Child outcomes are also influenced by the monetary and non-monetary investments parents make in their children, investments that influence their skills, beliefs, and motivation. These will reflect their degree of altruism, and their efficacy in translating time and money into long-run outcomes. Different sets of values will lead to different policy recommendations dealing with the extent of state intervention, and public provision of goods that compensate or substitute for parental and familial investments of this more subtle sort.

As such we should be cautious in drawing normative conclusions from observed differences. Policy recommendations cannot be drawn from the sort of cross-country comparison we have offered without additional information on social values that give meaning to "equality of opportunity," and define the legitimate methods to attain it.

For this reason we inform our analysis with two public opinion polls that address a host of issues related to economic mobility and equality of opportunity. The first was conducted for the PEW charitable trusts by Greenberg Quinlan Rosner Research in late January and early February of 2009; the second adapted this questionnaire to Canada and was put into the field in late August and early September of the same year by EKOS Research Associates. ${ }^{4}$

In what follows we report on just three aspects of these polls: (1) a definition of the "American Dream" and its association with economic mobility; (2) a statement of perspectives on the factors that influence economic mobility; and (3) a description of concerns about inequality, equality of opportunity and the role of public policy.

In the United States respondents were asked the following question:

The term American Dream means different things to different people. Here are some ways some people have described what the American dream means to them. On a scale of one to ten, please tell me how accurately each statement describes what you consider the

\footnotetext{
${ }^{4}$ The poll of Americans surveyed 2,119 adults older than 18 years between January 27th and February 8th, 2009. This was based on random digit dialling with the use of a cell phone sampling frame for those under 40 years of age, and took an average of 22 minutes to complete. The poll of Canadians surveyed 1,035 adults 18 and older between August 20th and September 14th, 2009. This survey was also based upon a stratified random sample including both land line and cell phone households. The questionnaire was the same as that used in the American survey to the extent possible. Some questions were adapted, some added, and everything was also translated to French. It required an average of 29 minutes to complete. See http://www.economicmobility.org/poll2009 for the questionnaire used in the United States, and a summary of the major results. The Canadian questionnaire is available from the authors upon request.
} 
Figure 5: Defining the American Dream in the United States and Canada: Per cent responding eight or higher on a ten point scale

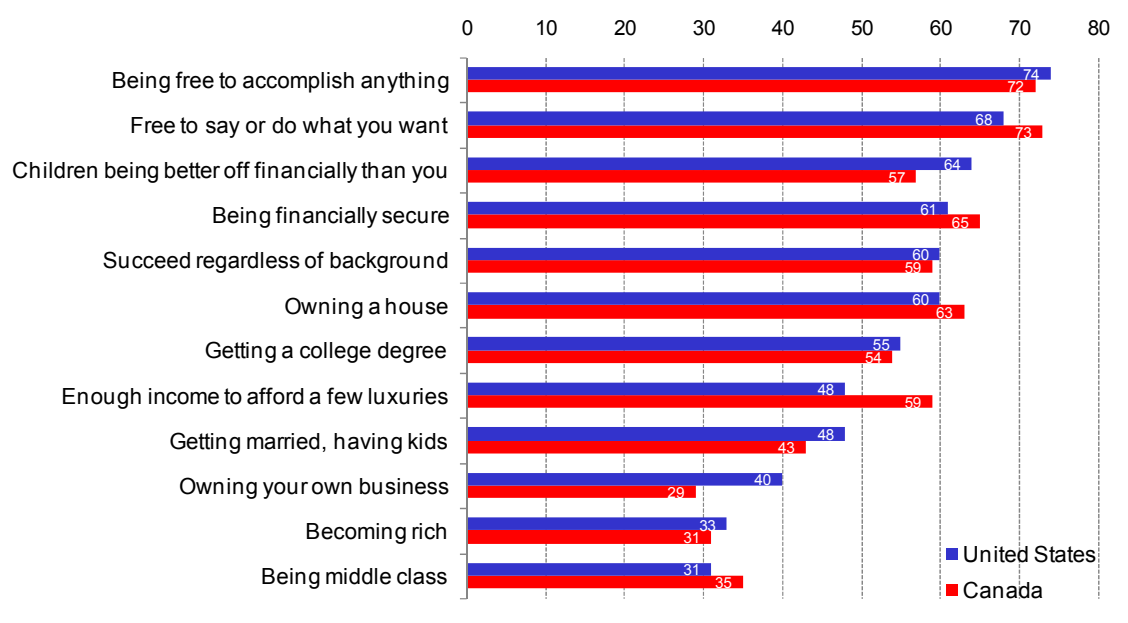

American dream to be. One would mean this statement does not describe the American Dream at all. A ten would mean this statement describes the American Dream almost perfectly.

This was the most challenging question to adapt to the Canadian situation, and it was posed as:

Americans often talk about attaining the American Dream to describe what it means to have a good life in their country. This means different things to different people. Here are some ways some Americans have described what the American Dream means to them. On a scale of one to ten, please tell me how accurately each statement describes what you would consider the Canadian Dream to be. One would mean the statement does not describe what it means at all. A ten would mean the statement describes it perfectly.

The outcomes are very similar, and are presented in Figure $5 .^{5}$ The information in this figure presents the proportion of the sample answering 8 or higher on a 10 point scale. Americans and Canadians have for the most part the very same ranking of these alternatives, and indeed in very much to the same degree. The two options that garner the greatest consensus, in the neighbourhood of

\footnotetext{
${ }^{5}$ The 95 percent confidence interval for the US survey is $+/-3.4$ percentage points at sample proportions of 50 percent, falling to $+/-2.0$ percent at 10 and 90 percent. These bounds are similar in Canada, with the 95 percent interval being $+/-3.0$ percent at a proportion of 50 percent. With respect to this particular question, the option "Getting a college degree" was changed in the Canadian version to "Getting a university degree."
} 
70 percent, refer to aspects of individual freedom. Aspects of financial security follow next with about 60 percent of the samples giving the financial welfare of children, financially security, and house ownership a score of eight or higher out of ten. Canadians differ from Americans in being somewhat more content with being able to afford a few luxuries, and less inclined to feel strongly about owning a business. But the general message from this information is that there are not strong underlying differences in what the good life means, and most importantly it is associated with individual freedoms.

The citizens of these countries also have similar views concerning the factors that determine economic mobility. Both Americans and Canadians feel strongly that individual attributes, like hard work and schooling choices, lead to upward economic mobility. In both countries factors external to the individual, outside of his or her control, rank much lower. The same question was posed in both countries:

Some people use the term ECONOMIC MOBILITY to describe the ability of individuals to move up or down the income ladder over a lifetime or from one generation to the next. I am going to read you a list of factors that may contribute to a person's economic mobility, that is, their ability to improve themselves financially and get ahead in life. For each one I read, please tell me if this is essential, very important, somewhat important, not very important or not important at all?

Figure 6 displays the proportion of respondents that said the factor in question was essential or very important to upward mobility. Five items in this list garner this level of support from three-quarters or more of respondents in both countries, and with the same ranking. All of these refer to personal choices related to effort or with human capital formation: hard work, having ambition, staying healthy, quality Kindergarten to Grade 12 education, and more generally having a good education. "Growing up in a stable family" also is highly cited, with over 70 percent of respondents considering it an essential or important factor in determining economic mobility.

The distinction between factors reflecting individual choices and others reflecting external contexts is admittedly a bit blurred. For example, "quality education" is both an individual decision reflecting choices about how much education to receive and at which schools, but also one that is constrained by social and institutional structures. This said, other factors that are, to varying degrees, outside of the individual's control received less support. Though, when these refer to aspects of family background, and individual characteristics like race and gender, respondents in the United States are more likely to consider them essential or very important. Having educated parents, coming from a wealthy family, gender, and race all rank among the lowest in the entire list, but with more Americans citing them than Canadians. ${ }^{6}$

\footnotetext{
${ }^{6}$ The differential impact of the 2008/09 recession and the differences in when the two surveys were put into the filed is revealed in the much higher percentage of Americans seeing
} 
Figure 6: FFactors determining upward economic mobility: Per cent responding essential or very important

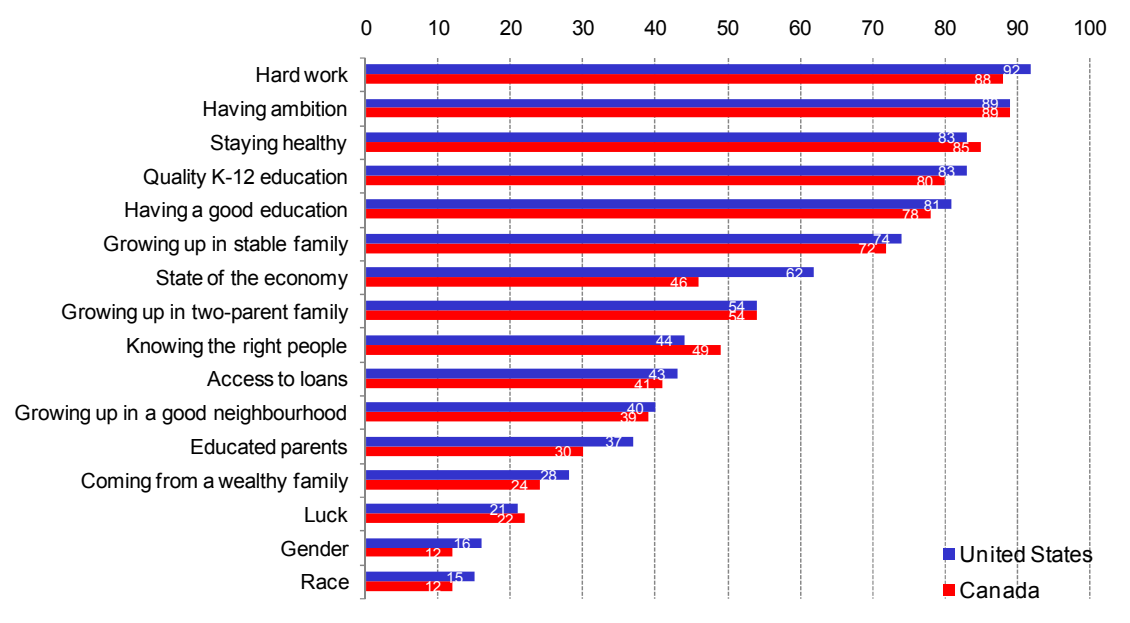

Further, results from the World Values Survey corroborate this conclusion. The 2005-06 wave of this international survey asked slightly over 2,000 Canadians and about 1,200 Americans a series of related questions. Two of the most pertinent asked for the level of agreement with the following statements: (1) "In the long-run hard work usually brings a better life"; (2) "Some people feel believe that individuals can decide their own destiny, while others think that it is impossible to escape a predetermined fate". On a ten point scale, 49 percent of respondents from each country indicated a high level agreement to the first statement (answering 1, 2 or 3 on a ten point scale), while in response to the second statement 45 percent of Americans and 53 percent of Canadians felt that people shape their own lives (similarly answering among the top three levels of agreement on a ten point scale).

As might be expected from these findings Americans and Canadians also have similar attitudes toward equality of outcomes and equality of opportunities as public policy priorities. Respondents were presented with a series of facts about the degree of economic mobility drawn from the academic literature, including most notably the facts about the degree of mobility at the top and bottom of the earnings distribution described in Figures 2 and 3. The question is stated as follows:

I am going to read you some facts about economic mobility in this country. After each one I read, please tell me whether you believe

the state of the economy as being essential or very important. This said, the survey also found that 79 percent of Americans believe that it was still possible for people to get ahead during the downturn. 
this represents a major problem for this country, a minor problem, not much of a problem or no problem at all:

- About (40 percent of Americans / one-third of Canadians) who are born to parents at the bottom of the income ladder are still there as adults.

- More than 30 percent of children who are born to parents at the top of the income ladder are still there as adults.

Exactly the same majority of respondents in the two countries- 53 percentsuggested that the difficulties in moving upward for those born at the bottom was a major problem, while a much smaller proportion - 17 percent in the United States and 12 percent in Canada-suggested that the persistence in status of those born to the top was a major problem. These patterns are essentially the same when reference is made directly to the distinction between equality of outcomes and equality of opportunities as public policy problems. In responding to the question "What do you think is more important for this country: to reduce inequality, or to ensure everyone has a fair chance of improving their economic standing?" 71 percent of Americans and 68 percent of Canadians cited ensuring a fair chance, while respectively only 21 percent and 26 percent cited reducing inequality. ${ }^{7}$

The most notable difference between the two countries concerns the role of government as a means of influencing economic mobility. The question "Generally speaking, do you think the government does more to help or more to hurt people trying to move up the economic ladder?" does not garner majority support one way or the other in either of the countries. But 46 percent of Canadians feel that government does more to help than to hurt, compared to 36 percent of Americans. On the other hand, 46 percent of Americans feel government does more to hurt versus 39 percent of Canadians. ${ }^{8}$ These differences are wider than any other differences in responses to all the questions addressed to these two groups of citizens. ${ }^{9}$

In summary, both Americans and Canadians have a strong belief that to some significant degree individuals - through their own energy, talents, and

\footnotetext{
${ }^{7}$ The World Values Survey does not ask exactly the same question. However, it does ask for the level of agreement on a ten point scale to the following statement: "Incomes should be more equal". Roughly one-fifth to one-quarter of respondents in the two countries answered 1, 2, or 3 with 1 implying complete agreement. The Canadian percentage was just over one-quarter.

${ }^{8}$ The remaining 15 to 18 percent either responded both, depends, or neither.

${ }^{9}$ The major exception to this is the response to the role of the economy as a factor determining economic mobility, as depicted in Figure 6. This likely reflects the fact that the recession starting in the autumn of 2008 was felt much more strongly in the United States, and also that the American poll was put into the field only two or so months afterward. In Canada the recession, while significant, did not increase the unemployment rate to the same degree, nor did it have as significant impact on the housing sector. In addition, the Canadian poll was put into the field some ten months after it started. Americans are also more inclined to see their children as having living standards. But it is not clear how to interpret this finding. It could reflect differences in the severity of the recession if respondents are influenced by short term developments. Alternatively it could also reflect a longer term perspective, but be the result of the greater inequality at the bottom of the income distribution in the United States.
} 
Figure 7: Effectiveness of steps government could take to improve economic mobility: per cent responding very effective

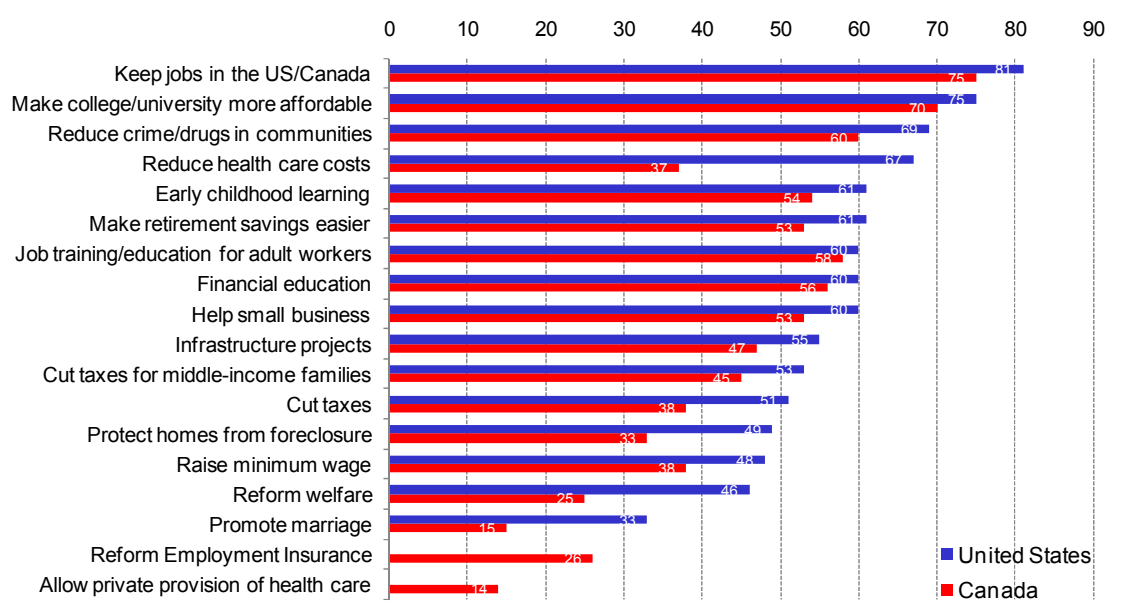

choices - determine their chances of success in life, and in particular prospects for upward mobility. At first look it is reasonable to suggest that a strong sense of individual responsibility, in both defining what it means to get ahead in life and in the way to achieve it, gives limited support for government involvement. But the conclusion that "Americans' strong emphasis on individual responsibility in determining economic mobility informs their understanding of government's role" does not entirely capture the full picture. ${ }^{10}$ This should not simply be interpreted as meaning that a strong sense of the individual implies a diminished role for public policy. Canadians emphasize individual responsibility to exactly the same degree, yet feel the government is more likely to support than than to hinder the individual. American attitudes could reflect, and be based upon, actual experience with government programs - their design and implementation, and a mismatch between the goals that they are ultimately addressing and those citizens would prefer - rather than an inherent aversion to government involvement.

In other words, the cross-country comparison raises the possibility that the American view that government does more to hurt than to help economic mobility is less a reflection of a belief as to what government should do, but rather an assessment of what it actually does. After all the American survey also points out that respondents believe there are effective steps government could undertake to improve economic mobility. These are illustrated in Figure 7, which shows that Americans are in fact more likely than Canadians to say-across the entire range of options put to them-that a particular intervention would be

\footnotetext{
${ }^{10}$ The quotation is from Economic Mobility Project (2009), page 16.
} 
very effective in promoting economic mobility. ${ }^{11}$

A couple of these options - cutting taxes and cutting taxes for middle income families - imply a smaller presence for government. These options are said to be very effective by a small majority of Americans, but by a minority of Canadians. This could reflect a greater preference among Americans for smaller government, or it could reflect a greater dissatisfaction with what government is actually doing with the revenues obtained.

But at the same time it should also be noted that tax-cutting ranks lower than many other options, all of which have strong majorities of American respondents saying they would be very effective. Very roughly there is a similar ranking of these options across the two countries, but-with the exception of promoting marriage - all of them obtain a majority or close to a majority opinion in the United States. In Canada only eight of sixteen receive majority support, with many garnering substantially less support than in the United States. The most graphic illustration of the differences between the opinions of the citizens of these two countries is in the case of health care. The different institutional context leads to two-thirds of Americans suggesting that a reduction in health care costs would be very effective, but only about one-third of Canadians feel the same way. In other words, the differences between the countries may in some degree be taken to reflect different perceptions of satisfaction with what their governments are actually doing, rather than just different values toward the underlying legitimacy of intervention.

If there is some validity to this interpretation of the findings, then there is actually more scope for increased government involvement in promoting economic mobility in the United States than in Canada. In some sense there might be an unmet need in the United States. As such it is important and informative to appreciate what public policy actually does to promote economic mobility.

\section{Two portraits of child well-being}

How different is the extent and the nature of investments these countries make in their children? Is child well-being and are child outcomes different as a result of these investments? And consequently to what extent can we expect the degree of generational mobility observed for the current generation of young adults to continue for the next generation?

We respond to these questions by loosely organizing a descriptive analysis of the well-being of children and the situation in which they are growing up around the framework developed by Solon (2004). Solon adapts the often cited

\footnotetext{
${ }^{11}$ The exact wording of the question is: "Now I am going to read you some steps the government could take in improving economic mobility in this country and giving people the opportunity to improve their chances of moving up the income ladder or the chances of their children. For each one I read, please tell me if you believe this would be very effective, somewhat effective, not very effective or not effective at all." The options "Reforming Employment Insurance" and "Allowing private provision of health care" are asked only in the Canadian survey. "Employment Insurance" is the official term referring to the country's unemployment insurance program.
} 
Becker and Tomes (1979) model of intergenerational mobility in way appropriate for comparisons across countries. The portrait we paint is also informed by a wide literature on the influence of early childhood development on long run outcomes, as exemplified for example by Knudson et al. (2006), but it is a portrait and not a rigorous causal analysis. Our description uses a number of nationally representative surveys and is addressed to a group of children who are newborns to 13 years of age just before the year $2000 .{ }^{12}$ These are children growing up during the 1990s and the first years of the new millennium, who in the coming decade or two will be the next generation of adults. In other words, they are the cohort who, when they become young adults in the coming years, will be the subject of the next wave of intergenerational mobility studies. But this also underscores an important caveat: the analysis does not refer to the situation of the most recent cohort of young people, nor to the institutional and policy setting since roughly the year 2000 that will determine their prospects.

To paraphrase, perhaps a bit too liberally, Solon (2004) we can imagine the adult outcomes of children being determined by three broad forces: the family, the labour market, and government policy. Families have different capacities and resources for investing in their children, and they face different incentives to do so according to socio-economic status and across countries. The degree to which inherent family traits and family specific investments are passed on to the next generation reflects a wide range of influences, some specific to the national context.

At the most general level families with more human and social capitalbroadly defined as education, health, geographic location and other attributes that increase long run capacities and labour market success but at the same time are subject to individual choice -invest more in their children. One aspect of this is that families with more children will invest less in each child. This should be understood as referring to the number of children per adult in the

\footnotetext{
${ }^{12}$ For the United States these include the 1999 National Survey of American Families (NSAF) and the 1999 Current Population Survey (CPS); for Canada they include the 1998 National Longitudinal Survey of Children and Youth (NLSCY) and the 1998 Survey of Labour and Income Dynamics (SLID). For both countries we also use The International Mathematics and Science Study (TIMMS). The NSAF and the NLSCY form the basis for a large part of the analysis. These data were the most comprehensive available at the time we began our research, to address issues dealing with the comparative study of the broad well-being of Canadian and American children. The majority of the information was derived from questions asked of the 'person most knowledgeable' about the child. This person was a woman for 92.3 percent of the Canadian children considered, and for 80.8 percent of the American children. Most often this woman was the biological mother of the child.

For some variables studied, for example family income, the NSAF and NLSCY do not provide the best available information. In these cases, we draw upon the CPS, the SLID and also for some American outcomes the 1999 National Longitudinal Survey of Youth, MotherChild Supplement.

All estimates reported are weighted, and we only describe differences between the countries that are statistically significant in the sense that the 95 percent confidence intervals around the point estimates do not overlap. This allows multiple comparisons, though the test is stronger than the usual tests for significant difference at the 5 percent level. Standard errors used to construct the confidence intervals take account of both the survey design and the fact that some children are siblings and hence not independent observations.
} 
family, so that a family of two parents and two children might be said to have fewer children per adult than a single-parent family with two children-putting issues of economies of scale in both time and money aside.

But it is important to emphasize that these investments are both monetary and non-monetary. Parental financial investments as well as the time they spend with their children are important in determining their well-being and long run capabilities. In some contexts time and money will be complements, in others they will be substitutes. But as Knudson et al. (2006) and others have emphasized, the early childhood development literature points to the important role of a child's attachment to the mother during the early years as an influence on socialization that also impacts on later developments and opportunities for the child.

But the capacity and the incentives to invest in children are also influenced by factors outside of the family, particularly how families interact and interface with the labour market and public programs. An increase in the cost of human capital investment, such as in market based provision of child care, private primary schooling, or college tuition fees, will lead to lower human capital investment. At the same time a higher return to human capital will create an incentive for more investment. Solon (2004) takes the rate of return to education as an indicator of the degree of inequality in the labour market, and shows that societies with labour markets characterized by more cross-sectional inequality - that is a higher return to education - will be less generationally mobile. Inequality in the here-and-now causally leads to more transmission of inequality across generations. Higher returns to human capital increase both the resources and capacities of families with high levels of human capital to invest in their children as well as the incentive to do so.

Public policy can both accentuate and dampen this influence of labour market inequality. Solon also shows that generational mobility is promoted by "progressive" public programs, those that are of relatively more benefit to the relatively less well off. As such it is not simply the level of public expenditures that is important, but rather how those expenditures are distributed according to socio-economic status. Indeed, his use of public programs is broader than just public transfers or publicly provided child directed programs. The term should be understood as referring to all aspects of public actions that influence the relationship between families and the labour market, which in addition to expenditures include the structure of taxation and regulations. An important example would be the use of a very narrow tax base such as local property taxes to finance public schooling, as opposed to progressive income taxes. The former is less "progressive" than the latter in that it likely implies higher quality schooling to those who are relatively better off. Globally, public intervention can give relatively more support to less well off families compensating them for more challenging family situations or a lack of a foothold in the labour market, or it can be of relatively more benefit to the well off. The more unequal the labour market the more challenging this role, one that could also to some degree crowd out private investments. 


\subsection{Parents, families, and family life}

Parents and families are central to the well-being of children in both the hereand-now, but also over the longer term as they grow into adulthood. Children require the material sustenance money can buy, but also the non-material care flowing from the time they share with their parents and other care-givers. The findings in this section sketch the circumstances that might offer both opportunities and challenges for parents to meet the monetary and non-monetary needs of their children.

Age, ethnic background, and immigrant status in a rough way all signal the extent and types of networks parents have and potentially how well established they are in the labour market. In particular, younger mothers are typically less secure economically insofar as they have not had time to finish an education, have not found a secure job, and face much higher rates of unemployment than older mothers. Parents offer not only monetary support to their children, they also offer time. Research indicates that, even after controlling for economic status, outcomes for children whose mothers were very young at the time of the child's birth are on average not as good as outcomes for children with older mothers. Young mothers may face a host of stresses associated with a lack of parenting experience and family support. Indeed, family structure is often cited as one of the most important determinants of child attainments. Living in a small family with two biological parents may offer the highest odds of setting a child down a successful path; living with a lone-parent and in a large family may offer the lowest. ${ }^{13}$

Research also shows that the mother's education is a very strong correlate of child well-being and outcomes. But this association is strongest for mothers with low levels of education. Having a mother with very low education is linked with significantly worse outcomes for children, but high levels of parental education are not any more significantly tied to better outcomes than are intermediate levels. As a result differences between Canada and the United States in the post-secondary attainment of parents may not be particularly important for children. ${ }^{14}$

All of these characteristics and resources may influence parenting style.

\footnotetext{
${ }^{13}$ See for example Blum Munroe et al. (1988) and Dooley et al. (1998). The research is not entirely clear on the causal mechanisms at work. For example, two comparable studies-one using Canadian data and another American-both find that children who witness the divorce of their parents do not have inferior labour market outcomes in adulthood (Corak 2001, Lang and Zagorsky 2001). Other studies have pointed out that the negative or stressful experiences prior to separation of the parents may be the link with poor child outcomes, not the divorce per se. And still other studies suggest that what happens after wards may count. In particular, one American report has found that, at least with respect to certain aspects of health care, step-mothers tend to invest less in their children's well-being, the implication being that children in blended families may be at a disadvantage (Case and Paxson 2001).

${ }^{14}$ One exception to this pattern, however, is schooling outcomes, which tend to be strongly influenced by higher levels of maternal education. All this said it is again important to recognize that the causal mechanism from mother's education to child outcomes is, since the publication of Behrman and Rosenzweig (2002), the subject of debate. For a comprehensive overview of this literature see Holmlund et al. (2008).
} 
Given the centrality of parents in the lives of young children positive parentchild interaction is often viewed as very important for child development and well being, with many studies noting that parenting styles are highly correlated with child-health outcomes. ${ }^{15}$ Mothers' physical and mental health is thought to have a strong association with child health status. Healthy mothers are thought to be most capable of adopting a parenting style of most benefit to their children.

For all of these reasons we begin by presenting information on the age and education of mothers, as well as other aspects of family size and structure. Some of the major findings are summarized in Table 1.

Canadian and American children are about the same age, but their mothers are not. ${ }^{16}$ While mothers are on average about the same age, this masks very different underlying distributions. Canadian children have mothers who on average are 35.5 years old, while American children have mothers who are 34.3 years of age. But Canadian mothers are noticeably more likely to be aged 35 to 44 years (48.9 percent) than American mothers (39.1 percent). Almost nine percent of American mothers are less than 24 years of age, but in Canada only half that proportion fall into this age group. The same general pattern holds for fathers present in the household.

This corresponds to the fact that there are differences across the countries with respect to the age at which women gave birth. Teenage births are much higher in the United States. In Canada 2.1 percent of children 13 years or younger were born to teen-aged mothers, but in the United States this figure-at 8.3 percent-is almost four times as high. These differences are still noticeable when slightly older mothers are considered. Just less than one in seven Canadian children (15.3 percent) were born to mothers aged 20 to 24 years, but almost one in four American children (24.6 percent) had mothers in this age group at birth. As a result there are proportionally many more very young mothers in the United States. ${ }^{17}$

\footnotetext{
${ }^{15}$ Parenting styles are sometimes classified as being at one extreme permissive, and at the other authoritarian. It has been suggested that the style of greatest benefit to children involves neither of these, but rather a positive-authoritative interaction. While still acknowledging the importance of parenting style other researchers have pointed out that attributing causality to correlations can be difficult. Parenting style may be as much a response to children's behaviour as a cause of it (Cadman et al. 1991 and Burton et al. 2002).

${ }^{16}$ In the NSAF and NLSCY data we use about 20 percent of children are two years of age or younger, 14 percent are between the ages of three and four, 45 percent are five to ten years of age, and about a fifth are 11 to 13 years of age in both countries.

${ }^{17}$ That on a proportional basis four times as many American children are born to a teenage mother is a striking difference between Canada and the United States. But it is necessary to put this fact into a broader perspective. A comparison of teenage pregnancy rates that includes all of the rich countries reveals, firstly, that the United States stands out as having an exceptionally high rate, and secondly, the rate in Canada is not particularly low, in fact just the contrary.

Using 1998 data, UNICEF (2001) compares the number of births to women aged 20 or younger in 28 rich countries. The United States had a rate of 52.1 births per 1,000 women 15 to 19 years of age, much higher than any other country. The next highest rate was 30.8 , recorded by the United Kingdom. Thus, an observation that the teen birth rate in Canada is lower than in the United States should not be surprising, as this would be true of every other
} 
Table 1: The characteristics of families and parents in Canada and the United States for children 13 years of age or younger in the late 1990s

\begin{tabular}{|c|c|c|}
\hline & Canada & United States \\
\hline Proportion of children born to teenagers & 2.1 & 8.3 \\
\hline Proportion of children born to black mothers & 1.7 & 15.7 \\
\hline Proportion of children born to immigrants & 17.2 & 14.3 \\
\hline \multicolumn{3}{|l|}{ 1. Current marital status of mothers } \\
\hline Married or common law & 84.1 & 76.9 \\
\hline Single, divorced or separated & 8.9 & 13.0 \\
\hline Single, never married & 6.0 & 9.1 \\
\hline \multicolumn{3}{|l|}{ 2. Family size ${ }^{1}$} \\
\hline No siblings & 19.3 & 19.9 \\
\hline One sibling & 46.0 & 40.0 \\
\hline Two siblings & 24.5 & 24.6 \\
\hline Three or more siblings & 10.2 & 15.6 \\
\hline \multicolumn{3}{|l|}{ 3. Family size in lone parent families ${ }^{2}$} \\
\hline No siblings & 32.9 & 23.9 \\
\hline One sibling & 41.8 & 33.9 \\
\hline Two siblings & 18.7 & 24.5 \\
\hline Three or more siblings & 6.6 & 17.7 \\
\hline \multicolumn{3}{|l|}{ 4. Education attainment of mothers ${ }^{3}$} \\
\hline Less than high school & 12.1 & 12.9 \\
\hline High school diploma & 17.6 & 31.3 \\
\hline Some post-secondary & 27.5 & 16.3 \\
\hline Post-secondary certificate & 25.0 & 14.5 \\
\hline University/College degree & 17.7 & 25.1 \\
\hline \multicolumn{3}{|l|}{ 5. Education attainment of lone mothers ${ }^{4}$} \\
\hline Less than high school & 20.6 & 19.3 \\
\hline High school diploma & 14.6 & 34.5 \\
\hline Some post-secondary & 34.4 & 18.3 \\
\hline Post-secondary certificate & 22.0 & 14.5 \\
\hline University/College degree & 8.4 & 13.4 \\
\hline
\end{tabular}

1. Percent of all children 13 or younger.

2. Percent of all children 13 or younger living in lone mother families.

3. Percent of all children 13 or younger with a mother present.

4. Percent of all children 13 or younger living in lone mother families.

Source: Tabulations by authors using weighted data from Statistics Canada, National Longitudinal Survey of Children and Youth, and the National Survey of American Families. 
Canadian mothers are more likely to be in their late 20 s or early 30 s when their children are born. Almost 70 percent of Canadian children were born to mothers who were 25 to 34 years old. In contrast this is the case for only about 55 percent of American children. At the same time about one in eight children in both countries had mothers 35 or older at the time of birth (13.7 percent in Canada and 12.7 percent in the United States).

Significant proportions of children in both Canada and the United States have either a non-white or immigrant background. The proportion of black children is higher in the United States, almost 16 percent having a black mother compared to only 1.7 percent in Canada. But children whose mothers are neither white nor black constitute 9.7 percent of the population in Canada and 6.1 percent in United States. ${ }^{18}$

Canadian and American children live in very different types of families. In Canada children are much more likely to be living with a mother who is currently married, and even more likely to be living with both of their biological parents. In the United States children are more likely to be living with step-parents and in lone-mother families. Just over 84 percent of Canadian children live with a mother who is currently married (both legal and common law), while 77 percent of American children are in the same situation. In Canada, about nine percent of children live with mothers who are single because they are divorced or separated, and a further six percent with mothers who were never married. Both of these proportions are significantly higher in the United States.

But the current marital status of the mother hides some important differences in the nature of families between the two countries. In Canada, 78 percent of children 13 years and younger live with both biological parents, substantially greater than in the United States where only 65 percent of children do so. As such there is a larger difference in the proportion of children living with two biological parents than there is in the proportion living with a currently married mother. This implies that more children in the United States live with stepparents. Over seven percent of American children have a step parent, compared to 5.5 percent of Canadian children. ${ }^{19}$

American lone mothers tend to be younger than their Canadian counterparts, and more likely to have given birth as teenagers. Almost 15 percent of American lone mothers are less than 25 years of age, compared to about 11

developed country.

Compared to these countries the Canadian rate of teenaged births is high. UNICEF found, that in addition to the United States and the United Kingdom, six other countries ranked in the top third with rates ranging from 20 to 30 births per thousand. Canada is among these, having a rate of 20.2 births per thousand teenagers.

${ }^{18}$ Inter-racial couples are not common in either country, though slightly more likely in the United States, amounting to five percent of American children versus 3.8 percent in Canada.

${ }^{19}$ While there are more lone-mother families in the United States than in Canada, reasons for lone parenthood are the same. The most common circumstance is divorce or separation. Of all children living in lone-mother families 57 percent in Canada and 53 percent in the United States have mothers who are separated or divorced. Having a mother who never married is also very common, making up 38 percent of the Canadian total and 42 percent of the American. 
percent in Canada. The bulk of Canadian lone mothers-more than four out of very ten-are between 35 and 44 years of age. This is a substantially higher proportion than in the United States. Furthermore, a much higher fraction of children 13 and younger living with lone-mothers were born when she was a teenager. This is the case for more than 15 percent of these children in the United States and less than 10 percent in Canada. Another difference between lone mothers in Canada and the United States has to do with the fact that in Canada close to 85 percent are white - not much different than the 89 percent of all mothers who are white-while in the United States only about 55 percent of lone mothers are white (versus 78 percent of all mothers). Over four out of every ten lone mothers are black, yet black mothers account for just less than 16 percent of all mothers.

Most children in both countries live in families with one other sibling, though it is much more likely to be in a family of four or more children in the United States. Up to 46 percent of Canadian children and 40 percent of American children have only one sibling. About one in four children live in a family of three children and one in five are only children. While living in a family with four or more children is the least likely scenario, it is still relatively common. This is particularly true in the United States where close to 16 percent of children are in this situation.

In Canada, lone mother families are smaller than other families; the most common arrangement in both countries is one with two children. Over 40 percent of children in lone mother families have one sibling in Canada, and about 34 percent in the United States. But having no other siblings is also common in these types of families, albeit more so in Canada than in the United States. Fully one in three Canadian children who live with a lone mother have no siblings, but in the United States this is one in four. At the same time a greater fraction of American children with lone parents live in families of three or more children. Children in lone mother families in the United States are slightly more likely than are other children to have two or more siblings. In contrast, Canadian children in lone mother families are much less likely to have two or more siblings than are children in other families.

The fraction of parents not completing high school in Canada and the United States is about the same, but in Canada a larger fraction have gone on to some form of post-secondary education. About 12 to 13 percent of mothers have not completed high school. In Canada, however, 27.5 percent of mothers have some post-secondary education while 17.6 percent have a high school diploma. Almost the reverse is true in the United States, with 16.3 percent having some post-secondary education and almost one-third with a high school diploma.

Having a post-secondary certificate or diploma (other than a university degree) is more likely in Canada, while in the United States mothers are more likely to have degrees. These differences may reflect differences in the structure of education systems across the two countries, with certificates being more commonly granted by Canadian community colleges which are outside the university 
system..$^{20}$

Education levels are considerably lower for lone mothers compared to married mothers. They are much more likely to have very low levels of education, and much less likely to have high levels. But the differences between the two countries mirror the patterns for all mothers. One-fifth of children in lone mother families are living with a mother who does not have a high school diploma. Lone mothers are half as likely to have completed a university degree as married mothers, but this fraction is higher in the United States.

The NLSCY and the NSAF also show that while parents on both sides of the border report themselves to be in good health, lone mothers and low-income mothers report lower health status, particularly in the United States where onein-five lone mothers say they are in poor or fair health. As documented in Table 2 nine out of ten lone mothers in Canada report being in good or better health, while fully one-in-ten report fair or poor health. In the United States the proportion of lone mothers reporting fair or poor health at 21.3 percent is twice as large. In addition, the mental health of lone mothers and low income mothers is significantly inferior to other mothers. In Canada about one in twenty lone mothers and low income mothers experienced a mental health problem that persisted for at least an entire week. About seven percent felt depressed for all or most of a week, and about five percent reported being "unable to shake the blues" or not feeling happy. This is significantly greater than the two to three percent of mothers overall who feel the same way. The same general patterns hold in the United States with about double the proportion of lone mothers and low income mothers reporting mental health problems all or most of the time relative to mothers over all.

It is difficult to obtain comparable measures of parenting style across these two countries with these surveys. One comparable indicator of parent-child interaction is the extent to which children are read to. This falls short of characterizing the nature of parenting style, but the data do show that approximately 64 percent of Canadian children and 46 percent of American children are read to daily. One-quarter of Canadian children and one-half of American children are read to between 1 and 6 days per week. Children who are never read to comprise nearly 10 percent of the group of Canadian children between the ages of 0 and 5 ; the comparable number in the United States is 7 percent.

The proportion of children who are never read to is higher in lone mother families and particularly in low income families, in both countries. Fewer children in these families are read to daily in comparison with all children, although a higher proportion of these children in Canada are read to daily than of comparably situated children in the United States: 54.4 percent versus 36.4 percent of low income children; and 58.9 percent versus 37.6 percent of the children of

\footnotetext{
${ }^{20}$ The pattern is much the same when fathers present in the household are compared. Roughly the same fraction of children has fathers with less than high school, but more fathers in the United States have a high school diploma. It is also more common for Canadian fathers to have a post-secondary credential, but less likely to have a university degree. FurchtogottRoth et al. (2009) discuss the need for a greater role for community colleges in promoting economic mobility in the United States.
} 


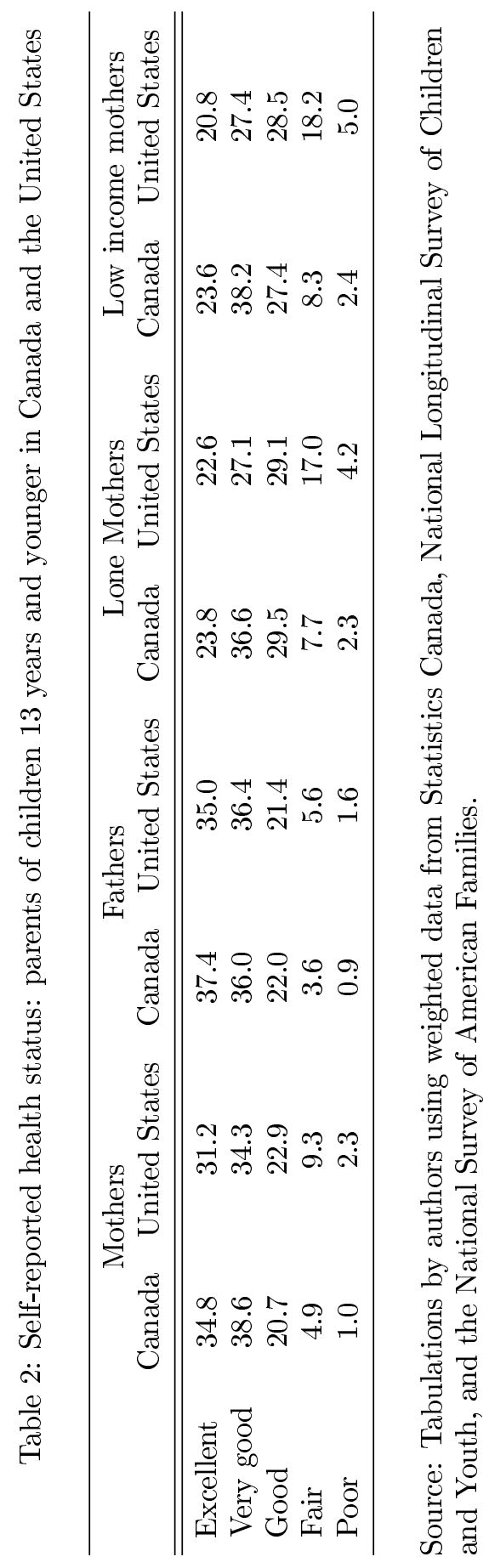


lone mothers.

\subsection{Work and child care arrangements}

Parental participation in the labour market is both cause and effect of child care arrangements. The choice or need to work means that parents must find alternative arrangements for their children; the availability of care outside of the home offers opportunities to work or to work more hours.

In this section we begin by noting that Canadian mothers of the cohort of children under study have higher rates of labour-force participation than American mothers, but mothers and fathers who are in the labour force work longer hours in the United States. On this basis alone it is not immediately apparent how labour market engagement influences the overall demand for day care, or how differences in social policy and family structure influence work patterns.

However, there are very clear differences in child care policies and social support between the two countries. Parental benefits are much more generous in Canada. During 1998 Canadian mothers who had worked a minimum of 700 hours over a 52 week period received 15 weeks of maternity benefits equivalent to 55 percent of past earnings. Another 10 weeks of leave could be taken under the same conditions by either the mother or the father of a newborn, though generally this parental benefit was taken up by mothers. Thus in Canada new mothers who had sufficient work experience were being provided with the opportunity to stay home for up to 25 weeks after the birth of their child. In 2001 this package of benefits, administered by the federal government through the national unemployment insurance program, was extended to one year. Maternity benefits are much more limited in the United States. Parents are entitled to 12 weeks of leave without pay if they work in a company with more than 50 people. This covers only about half of women in the work force.

National day care programs are not offered in either country. In Canada child care is organized provincially, with some provinces offering universal programs, and others subsidizing certain child-care facilities or offering subsidies or tax deductions to parents. In the United States child care is publicly provided for some vulnerable children under the Head Start programs, and there is limited funding through the federal government for low-income working families through the Child Care Development Fund Block Grant created in 1996. It has been estimated that only about 12 percent of eligible children are receiving this support. These funds can be used for child care services, and a state can also waive fees for families below the poverty line.

Families engage with labour markets in very different ways in these two countries, and the institutional context set by public policy is also very different. In the United States more mothers either work full-time or not at all. Almost 30 percent of mothers in the United States are not in the paid labour force; in Canada just under a quarter did not work. At the same time four out of every ten children American children had mothers who worked 40 or more hours per week, the most common arrangement. Only one quarter of Canadian children 
had mothers who worked 40 or more hours per week. Lower hours of employment are much more common in Canada with about half of children having mothers who worked less than 40 hours per week. This was the case for less than onethird of children in the United States. In both countries it is relatively rare that mothers work more than 50 hours per week, but at the same time not uncommon. Over seven percent of children in the United States and five percent in Canada had mothers working these very long hours. ${ }^{21}$

In both countries the work week is much longer for fathers than it is for mothers, with fathers in the United States in the late 1990s working more than their Canadian counterparts. Not working at all is rather uncommon for fathers in both countries, and the likelihood of part-time work is also not as likely as it is for mothers. In both Canada and the United States about one-half of fathers work 40 to 49 hours per week. But working even longer hours is significantly more common in the United States, with almost 40 percent in this situation compared to about 30 percent in Canada.

As a result of these patterns one-in-ten children of married couples in the United States have parents who together work over 100 hours per week. This high commitment to paid work is much less common in Canada, occurring for only two out of every hundred children. The most common arrangement in the United States is for parents to work from 80 to 99 hours per week. About 33 percent of children in the United States are in this situation, and about 25 percent of Canadian children. In contrast the most common arrangement in Canada is for parents to be working between 60 and 79 hours per week. Just over 35 percent of Canadian children are in such a situation, compared to 25 percent of American children.

In the United States lone mothers are more likely to be working than married mothers. Only about one-fifth of lone mothers do not work any hours per week, but this is the case for almost one-third of married mothers. In Canada these proportions are almost exactly reversed. Furthermore, just over 48 percent of lone mothers work more than 40 hours per week in the United States, almost double the Canadian proportion.

The flip side to these employment patterns are differences in care arrangements for infants and toddlers, pre-schoolers, and school-aged children. The majority of infants and toddlers in Canada are cared for by their parents; in the United States the majority is in some other type of care. Fifty-six percent of all children up to two years of age are cared for exclusively by their parents in Canada, compared to 40.7 percent in the United States. This difference likely reflects the very different maternity and parental leave available in Canada for working mothers of newborn children. The labour force participation of mothers with children less than one year of age is much higher in the United States and no different than that for mothers as a whole. In the United States 29.8 percent

\footnotetext{
${ }^{21}$ Labour force participation rates are somewhat, though not dramatically, lower for mothers of children less than five years of age. In the United States 32.1 percent of mothers with preschoolers were not engaged in paid work, compared with 29.8 percent of all mothers. In Canada this proportion is at 30 percent a little lower, and is compared to 24.8 percent of all mothers.
} 


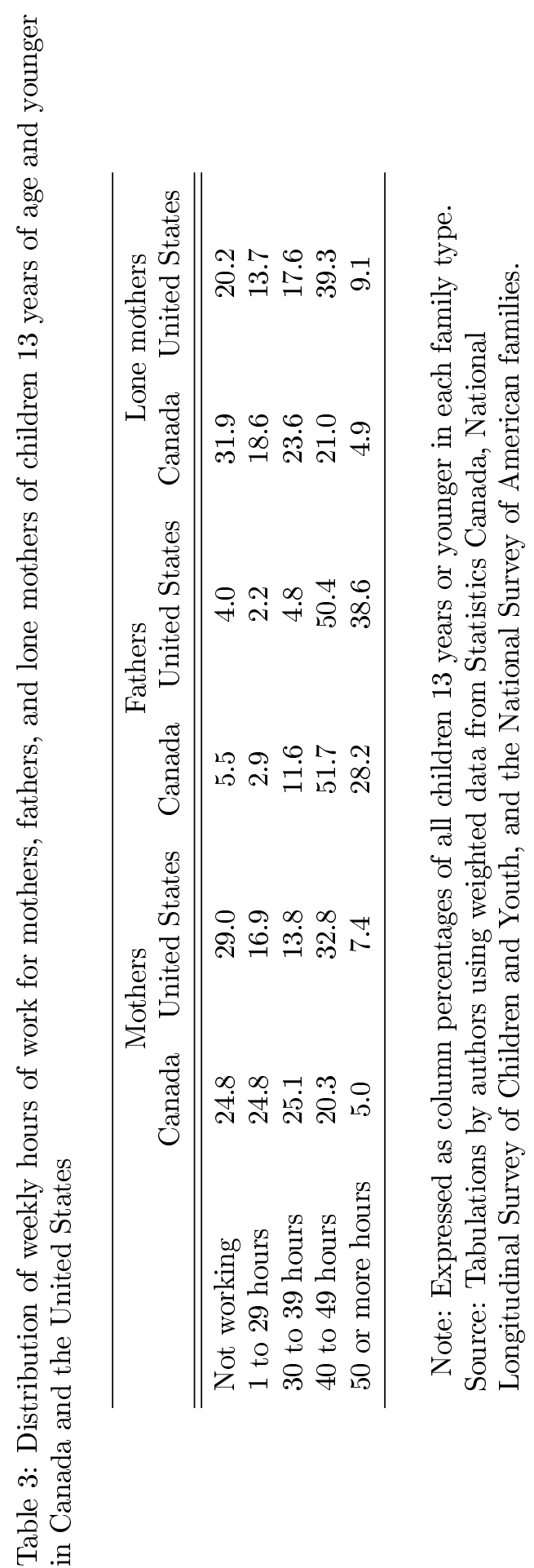


Table 4: Child care arrangements in Canada and the United States

\begin{tabular}{lcc}
\hline & Canada & United States \\
\hline \hline 1. Children 3 to 4 years of age & & \\
Parental Care & 45.4 & 23.1 \\
Day care centre & 12.4 & 34.3 \\
Cared for by a relative & 15.2 & 21.3 \\
Cared for by a non-relative & 25.1 & 12.6 \\
\hline 2. Children 5 to 10 years of age & & \\
in lone mother families ${ }^{2}$ & & \\
Parental care & 48.1 & 27.7 \\
Day care centre & 3.7 & 5.6 \\
Before/after school program & 7.7 & 17.7 \\
Cared for by a relative & 18.9 & 30.9 \\
Cared for by a non-relative & 17.6 & 12.4 \\
\hline
\end{tabular}

1. Expressed as a percentage of all children 3-4 years of age.

2. Expressed as a percentage of all children 5-10 years of age.

Totals do not add to 100 as not all child care options are considered.

Source: Tabulations by authors using weighted data from Statistics

Canada, National Longitudinal Survey of Children and Youth, and

the National Survey of American Families.

of women with an infant - or virtually the same fraction as all mothers-report that they do not work. In Canada, 35.6 percent of mothers with newborns report not working versus 24.8 percent of all mothers. ${ }^{22}$

Over three-quarters of pre-schoolers are in some type of non-parental care arrangement, while only about one-half of Canadians under five years of age are in this situation. Pre-schoolers in the United States are on average three times more likely to be cared for in formal day care centres than in Canada. These facts imply that the longer work hours of mothers and fathers creates more of a demand for non parental care than the higher overall labour market participation in Canada, a tendency consistent with flexible work arrangements permitting more part-time employment among Canadian mothers.

The majority of children five to ten years of age in Canada receive parental care only (54.6 percent). The figure is significantly lower but still substantial in the United States at 40.7 percent. In both countries an additional one-fifth of children of these ages are cared for by a relative, and largely in the child's own

\footnotetext{
${ }^{22}$ This said, while more young children in the United States are in non-parental care, the over all pattern in the type of care is fairly similar in the two countries. In both countries an infant is most likely to be cared for by a parent. In the United States care by a relative is the second most likely situation, with care by relatives and non-relatives being about equally likely in Canada. A day care centre is the least likely care arrangement for an infant or toddler in both countries.
} 
home. Of the remaining children aged five to ten proportionately more in the United States attend before and after school programs: about 14 percent versus only about five percent in Canada. In both countries only a small fraction of children look after themselves when their parents are working, with just over three percent in the United States and two percent in Canada for whom this is the case.

As the second panel of Table 4 illustrates, there is about a 20 percentage point difference between the two countries in the fraction of the school aged children of lone mothers receiving non-parental care. Fifty-two percent of the five to ten year olds of these parents in Canada are in this situation and 72 percent in the United States. At the same time care by a relative is more common for the children of lone mothers who are receiving non-parental care in the United States than it is in Canada, with nearly one-third in this situation in the United States compared with one-fifth in Canada. As with all children, the children of American lone mothers are more likely to attend before / after school programs. More Canadian children, however, are separately cared for by a non-relative (17.6 percent versus 12.4 percent), either inside or outside the child's home. ${ }^{23}$

It is possible that day care has a wide variety of opposing impacts on child well-being. While high quality care might mitigate some of the disadvantages of limited early nurturing in dysfunctional families, for example, a reduction in the period of time during which young children can be breastfed might have a detrimental impact on their long-term health and well-being. One of the difficulties inherent in assessing the overall impact of child care is that the substitution of non-parental care for parental care has the potential to either increase or decrease the emotional and physical resources available to a child. If the availability of day care increases the ability of family members to work, for example, the ramifications may be both positive and negative for a child.

Bushnik (2006) offers a detailed description of child care arrangements in Canada, and documents that the use of day care increased between 1995 to 2003, most notably in Quebec. In this province day care usage doubled to include 52 percent of children six months to five years of age, a figure nearly double the national average rate of 28 percent. Underlying the shift in Quebec was the phasing in of a low-cost, universal day care program for young children between September 1997 and September 2000. Commencing at a highly-subsidized cost of $\$ 5$ per day, costs rose slightly in 2003 to $\$ 7$ per day. Baker, Gruber and Milligan (2008) find evidence in the NLSCY data that a number of outcome measures worsened for children in two-parent families in Quebec, including measures pertaining to aggression, motor skills and illness. Measures of parental health, mental health and parental and parent-child relationships also showed some evidence of deterioration. These results may be attributable to a variety of causes,

\footnotetext{
${ }^{23}$ Child care arrangements for children 11 and 12 years of age are very similar for both countries with greater than one-half in Canada and 45 percent in the United States receiving parental care only, one-fifth in each country taking care of themselves, and another one-fifth receiving care from a relative. Canadian children cared for by a relative are more likely than American children to be cared for in their own home.
} 
either involving the nature of the child care itself, or the increases in the labour market activity of mothers that were observed as a result of the introduction of the universal day care program. ${ }^{24}$

\subsection{Family income, low income, and inequality}

Children in the United States are on average significantly more affluent than those in Canada. After taxes and government transfers the resources available to the average child in the United States amount to $\$ 35,667$ versus $\$ 27,222$ in Canada, a difference of $\$ 8,445$ or 31 percent. On the basis of the methods used in the calculations this difference is equivalent to $\$ 16,890$ for a family of four. ${ }^{25}$ Labour market earnings are the major source of income in both countries, but this is significantly more so in the United States where 92 percent of children live in families relying upon the labour market for the majority of their income. This is the case for 83 percent of Canadian children.

On the other hand, there are marked differences in the structure of government transfers available to families with children in the two countries. Almost nine out of every ten children in Canada live in a family receiving some form of transfer income. The proportion of children in Canada receiving transfer income (including, for example, child tax benefits, both regular and maternity or parental Employment Insurance benefits, and social assistance) is close to double that in the United States ( 87.5 percent versus 45.8 percent). Those families receiving transfers get an average of $\$ 3,107$ dollars per child in Canada and $\$ 2,883$ in the United States. ${ }^{26}$

In Canada fully 85 percent of children in two parent families receive some form of income support from government, but this proportion is only 35 percent in the United States. These proportions are higher in both countries for children living in lone parent families. Virtually all (99.7 percent) of these children are in receipt of some amount of income transfer in Canada; 83 percent in the United States.

Despite considerably higher average incomes children in the United States are much more likely to be living in low income. During 199926.7 percent of U.S. children versus 17.1 percent of Canadian children lived below a low income threshold of one-half of median income. ${ }^{27}$ On average the depth of low income

\footnotetext{
${ }^{24}$ The authors also caution that the impacts may represent short-term, transitional and not long-term impacts, and that the potential exists for families to choose day care as a result of benefits that are not fully observable in the data.

${ }^{25}$ The difference in the median living standard is not as great but still significant. The median child has access to $\$ 27,442$ in the United States and $\$ 22,703$ in Canada, a $\$ 4,739$ or 21 percent difference. All monetary values are expressed in 1998 Canadian dollars, with all income information drawn from two surveys explicitly designed for the purpose, the 1998 Canadian Survey of Labour and Income Dynamics and the 1999 U.S. Current Population Survey.

${ }^{26}$ This does not account for the value of in-kind benefits in the United States, nor increases in the Earned Income Tax credit in recent years.

${ }^{27} \mathrm{On}$ the basis of the surveys used in this section the median income in Canada for 1998 is $\$ 22,703$, leading to a low income threshold of $\$ 11,351$; in the United States for 1999 it is $\$ 27,442$, implying a low income threshold of $\$ 13,721$. These derivations are based on samples
} 
is also greater in the United States. The average child in low income was 41.7 percent below the low-income threshold in the United States but 26.5 percent below in Canada. This amounted to $\$ 6,268$ in the United States and $\$ 3,213$ in Canada.

These differences are the result of the fact that transfer payments reduce the rate of low income in Canada significantly more than in the United States. In fact, labour markets lead to roughly similar rates of low income in both countries. About the same fraction of children would be in low income on the basis of solely parental labour market earnings: 27.1 percent in Canada compared with 30 percent in the United States. The depth of low income would be greater in Canada. On average Canadian children in low income would be 60.3 percent below the low-income threshold while American children would be 50.9 percent below.

While 63.2 percent of low income Canadian children live in families reporting some labour market earnings, for only 30.3 percent are earnings the major source. This is in contrast with low income children in the United States, where earnings are the major source of income for 77.6 percent. Earnings are a smaller share of total income in Canada because rates of labour force participation are lower for low income parents and because government transfers are more significant. In Canada 36.8 percent of low income families with children report zero earnings, while in the U.S. this is so for only 11.7 percent. Virtually all (99.9 percent) Canadian families of children in low income receive some form of transfer payment. Receipt of transfer income is also the norm in the United States but not as high, with 93.1 percent of low income families with children report receiving some amount of support.

In both Canada and the United States children are significantly more likely to be in the bottom of the country-wide income distribution. About 15 percent of children in each country are found in the bottom 10 percent of the income distribution for the entire population and only about 5 to 6 percent in the top 10 percent. While children in the two countries fit into their respective country income distributions in much the same way, the gap between a child at the top and one at the bottom is much larger in the United States. The child in the top 10 percent of the United States income distribution has on average over 14 times as much income as a child in the bottom 10 percent. In Canada this ratio is 7.5. The differences are also significant when the average middle income child is compared to the average child in the bottom tenth. In the United States the child in the middle of the income distribution has 4.6 times as much income as a child in the bottom; in Canada only 2.7 times as much.

These differences reflect the fact that the income distribution in the United States is much more unequal than in Canada, with a larger fraction of individuals having a much higher than average income and a larger fraction having a much

representing the entire population of each country, not just the children. One half of median income is a threshold currently highlighted by the Luxembourg Income Study, a research network and data archive directed to international comparative research. Accordingly our derivations follow this precedent, including the use of the square root of household size as the equivalence scale. 
Figure 8: Distribution of children in Canada and the United States in the American Income Distribution

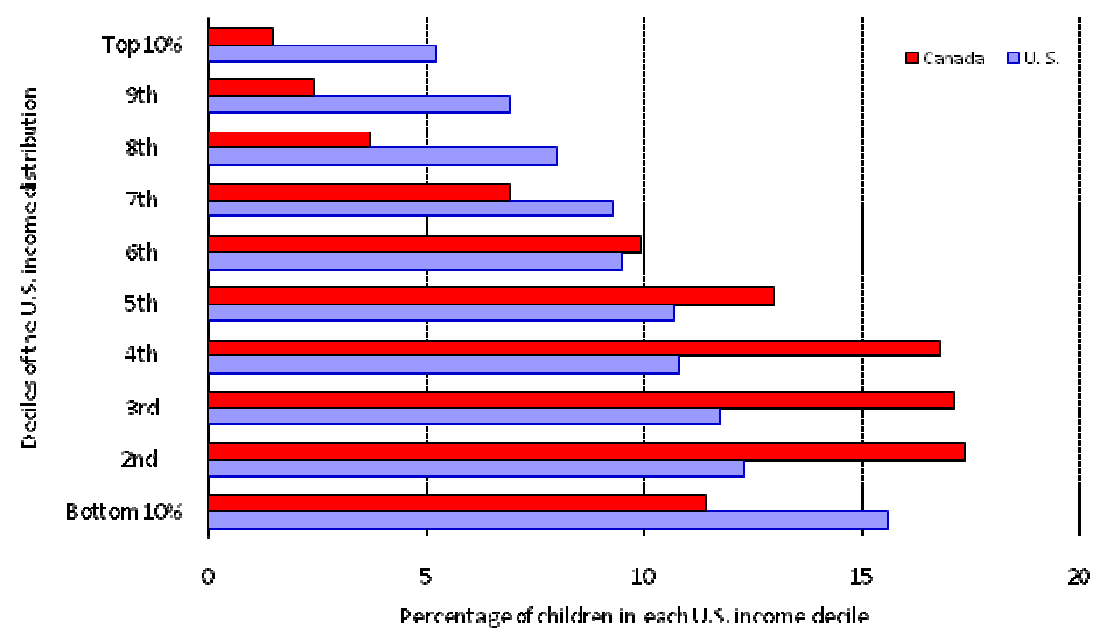

Source: Calculations by authors using 1999 Current Population Survey for the United States and 1998 Survey of Labour and Income Dynamics for Canada.

lower than average income. As Figure 8 illustrates, this also implies that the incomes of the strong majority of Canadian children would place them in the lower middle portion of the United States income distribution. Just less than two-thirds of Canadian children (64.2 percent) have incomes that would rank them above the bottom tenth of the income distribution but no higher than the middle. Only 24.4 percent of Canadian children have incomes sufficiently great to place them in the top half of the United States distribution, compared with 38.9 percent of United States children. The chances a Canadian child will be in the top tenth of the United States income distribution are only 1.5 percent versus 5.2 percent for American children. At the same time, Figure 8 also illustrates that Canadian children are less likely to have an income placing them in the bottom of the American income distribution. Only 11.4 percent of Canadian children would find themselves in the bottom 10 percent, a situation faced by 15.6 percent of United States children.

Other indicators of material well-being also point to the fact that Canadian children live in less extreme circumstances. Over three quarters (76 percent) of Canadian families with young children own the home in which they live. In the United States 63 percent of families with children own their homes. Rates of home ownership are much lower for low income families in both countries. In Canada four-in-ten low income families own the home in which they live, and 
in the United States 3.6 of every ten do so.

As well as being a proxy for wealth home ownership may also indicate a greater overall level of stability. Frequent residential moves, for example, have been shown to be a correlate of poorer outcomes for children. For example, Coleman (1988) treats residential moves as a marker for the disruption of the social capital and networks available to the family and child. In our data, over half of children between the ages of two and thirteen have moved at least once in their life time, with the proportion being higher in the United States and higher among low income children. In Canada 57.6 percent of children experienced a change of residence; in the United States 65.4 percent. Both of these percentages are greater for low income children. In Canada close to seven out of 10 low income children (68 percent) changed residence at some point in their lives; in the United States close to three-quarters (74 percent). About the same fraction of children from lone mother families in the two countries changed residences, 76 percent in Canada and 74 percent in the United States.

Living conditions are more crowded in the United States with 0.93 children's bedrooms per child versus 1.01 in Canada. Over one-fifth of Canadian children (22 percent) live in homes with a 'room to spare' compared to 18 percent of American children. In the United States, where there are larger families, almost half of children (46.9 percent) share a bedroom with a sibling, while about a third of Canadian children (34.3 percent) are in the same situation. Low income children live in more crowded arrangements in both countries, but more so in the United States where 70 percent share a bedroom and only 6.5 percent live in homes with extra bedrooms. In Canada 57.4 percent of low income children share a room and about 9 percent live in homes having more bedrooms than children or adults in the house.

\section{Early childhood outcomes and the prospects for economic mobility}

These configurations of forces-family structure and family life, care giving arrangements and participation in the labour market, and financial resources from the market and the state in both an absolute and a relative sense-all come together to determine the relationship between a child's socio-economic status and well-being in the here-and-now as well as capacities for succeeding in life. A series of intermediate outcomes links family background to adult outcomes. In particular, mental and physical health, as well as cognitive development and readiness to learn, have all been shown to vary with social and economic background, and in this section we document differences in these outcomes between Canada and the United States, and speculate on the prospects for economic mobility in the two countries.

It is not possible to sketch a direct causal link between the differences in resources available to children in these two countries, and the early outcomes that will influence their long-term prospects. But if there is a relationship our 
portrait of child well-being in Canada and the United States would suggest that differences in the prospects of the children on the two sides of the border should be evident even at the early ages which are the focus of our analysis. The cohorts of young children under study — particularly the relatively less well off-were being raised in more challenging family circumstances in the United States. Younger, less well-educated parents, who are more likely to also be single parents, and who must obtain a larger fraction of their income from employment yet have less flexibility in their choice of child care arrangements and hours of work, find themselves in more stressful situations. The challenges of providing for both the monetary and non-monetary needs of their children are greater for those at the bottom of the income ladder in the United States. In fact, the absolute disadvantages faced by these children is more severe than the situation of their relatively disadvantaged counterparts in Canada.

If these patterns had also held a generation ago it may not be surprising that bottom decile sons in Canada are as likely to move to the top half of the earnings distribution as third decile Americans. These differences in absolute advantage reflect not just more challenging family situations, but also the stronger presence of a more unequal labour market in family life. This presence is not given as large a counterweight with public programs, either through child care and leave policies, tax-transfer programs, or broad-based public provision of health care and public education of relatively more advantage to the disadvantaged. In this sense all three elements of Solon's model-family, labour markets, and public policy-offer less support to those at the bottom of the income distribution in the United States than in Canada.

The suggestion would be that the gap in the degree of generational economic mobility between these two countries described for a previous generation of young adults in the existing empirical literature is likely not to be narrowed for the children growing up during the 1990s, those who will come of age in the next decade or so. This is not a statement on the current configuration of public policy in the United States to the extent that it has changed for the cohort of children born since 2000 . But if this speculation has any validity then we should already begin to see differences in the outcomes relevant for economic mobility among the children who are the subject of our analysis. Consequently we focus on three related outcomes that interact in a recursive way to set a trajectory for a child and offer both risks and opportunities for long run success: mental and physical health; cognitive outcomes and readiness to learn; early education outcomes.

Empirical research has documented a strong positive association between income and health in adulthood, and that there are antecedents for this relationship in childhood. Poor health in childhood is likely to exert a long-run influence through two channels: directly through its influence on the person's likely health as an adult; and indirectly through its effects on schooling and the accumulation of other experience. An understanding of the relationship between family background and income on the one hand, and health in childhood on the other, may therefore signal the nature of the long term prospects for children living in low income families, and hence the probable degree of economic mo- 
bility. Recent research has highlighted the empirical observations that children with low socioeconomic status not only have worse health than do children with high socioeconomic status, but that the difference in health between the two groups is more pronounced for older than for younger children.

The study of this relationship, furthermore, benefits from a clear expected direction of causation, since child health likely does not determine child socioeconomic status. The same cannot be said of adult health. These findings have been derived from Canadian as well as American data, and exist in Canada despite the presence of universal public health insurance coverage of doctor and hospital services (Case et al. 2002, Currie and Stabile 2003, Oreopoulos et al. 2008, Phipps 2002, Smith 2009). The widening gap in the health of children of low and high socio-economic status as they age is hypothesized to stem from one of two factors: either low income children are less able to adapt to and recover from adverse health "shocks" than are other children, so the impacts of health events persist and accumulate for them; or, alternately, low income children respond similarly to single negative health events in the long term but are subject to a greater incidence of shocks over time. ${ }^{28}$

Table 5 shows that the mental health of children varies strongly with socioeconomic status in both the United States and Canada. Canadian and American mothers report that 70 percent of their children are never nervous, high strung or tense. Approximately one-fourth of their children sometimes exhibit these tendencies, and 3 in 100 children do so often. Although there are no significant differences noted between the United States and Canada for any type of household, children in lone mother or low income families in both countries are less likely to never be nervous, high strung or tense relative to children in all families. The difference is 9 percent in Canada and 6 percent in the United States. In Canada these children are nearly twice as likely as all children to exhibit these tendencies often.

About 60 percent of mothers in both Canada and the United States report that their children have never experienced concentration problems. As with nervousness and tension, no differences are apparent across countries, but children in lone parent and low income households in both countries are 10 percent more likely than are all children to have concentration difficulties.

At the same time, Canadian children are reported to be happier than American children. Mothers report that 75 percent of Canadian children and 66 percent of American children are never miserable, unhappy, tearful, or distressed. About one-fourth of Canadian children and one-third of American children are reported to sometimes be in this state, and 1 percent and 2 percent of Canadian and American children respectively are reported to be so often. The percentage of children often unhappy or distressed is slightly higher among low income or lone mother families in each country, but there are no significant differences

\footnotetext{
${ }^{28}$ Currie and Stabile (2003) use the NLSCY to demonstrate support for the second hypothesis. At the same time other research has demonstrated that low income or less educated individuals and their children may be hindered in utilizing health services by such economic and social barriers as the cost of transportation to visit health care providers, an inability to pay for prescriptions, and lack of knowledge as to how to navigate the health care system.
} 


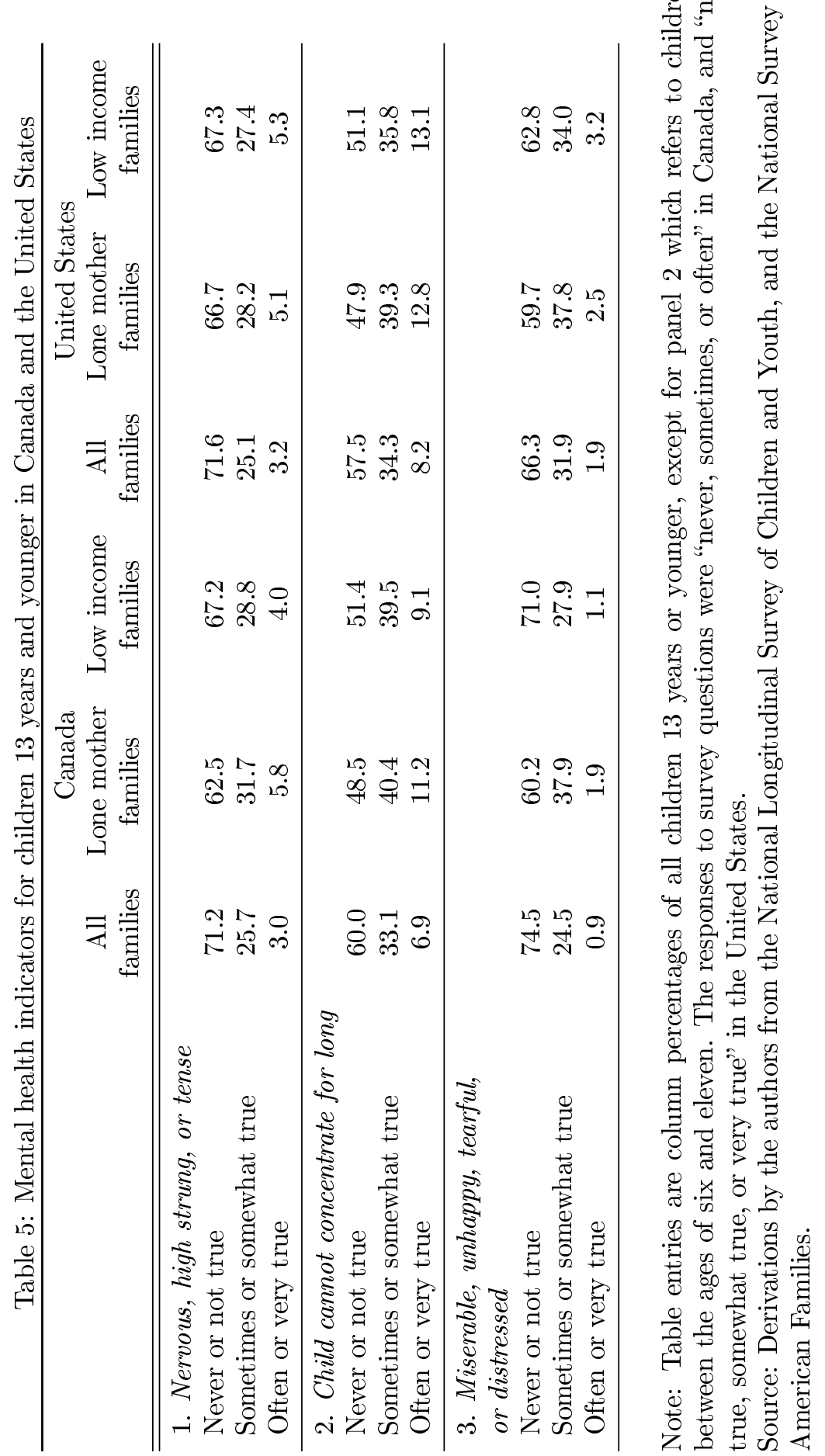


in rates for these family types between the two countries. At the same time, children in lone mother families are less likely than other children to never be miserable or unhappy. In Canada these children are nearly 15 percent less likely than other children to never be unhappy; the comparable gap in the United States is 7 percent.

Physical health of children also varies across these two countries. American mothers are more inclined to report their children as being in only fair or poor health. Approximately 60 percent of children in each country are reported to be in excellent health, and 29.2 percent in Canada and 26.4 percent in the United States are reported to be in very good health. At 4 percent versus 1.6 percent, more than twice as many children in the United States are reported to be in fair or poor health as in Canada. Although children in lone mother families are worse off relative to all children in both countries, Canadian children in these families fare better than their American counterparts, with 2 percent versus 7 percent reported being in fair or poor health. A similar pattern emerges with respect to low income children, with 3 percent in Canada and 7.6 percent in the United States reported to have either fair or poor health.

More Canadian than American children visit the doctor in a given year, and with greater frequency; the opposite is true of visits to nurses. Nearly 84 percent of Canadian children and 77 percent of American children make physician visits. Children in Canada on average also make a greater number of visits to physicians: 3.3 versus 2.7 per year. Nurse visits on the other hand are higher in the United States, with 35 percent of children in the United States and 19 percent of Canadian children receiving care from a nurse. The average number of nurse visits per child is also greater in the United States. These patterns likely have a good deal to do with the universal provision of health care in Canada. They are not, for example, evident with respect to visits to dentists, which in general are not covered by public health insurance in either country. Almost 80 percent of children aged 3 to 13 in both Canada and the United States make dental visits.

Children in lone mother and low income families are in general as likely as other children to see a physician in Canada. But while this pattern holds true in the United States for children from lone mother households, a slightly smaller proportion of American children from low income households, relative to all children, see a doctor during the year. In general the average numbers of doctor visits are alike across the different groups in each country, although in Canada the children of lone mothers and low income families make slightly more visits than do all children. ${ }^{29}$ Interestingly, this is not the case for visits to a dentist. In Canada only two-thirds of children from low income families, and three-fourths

\footnotetext{
${ }^{29}$ The relative similarities in the utilization of physician services within Canada and between the children of lone mothers and all children in the United States may seem somewhat surprising in light of the earlier observation that low income and lone mother children suffer on average from poorer health. This may be particularly true in Canada where public health insurance means that financial barriers to care should be limited; visit levels may therefore reflect other types of access barriers such as transportation issues or gaps in knowledge regarding children's care needs and available services.
} 


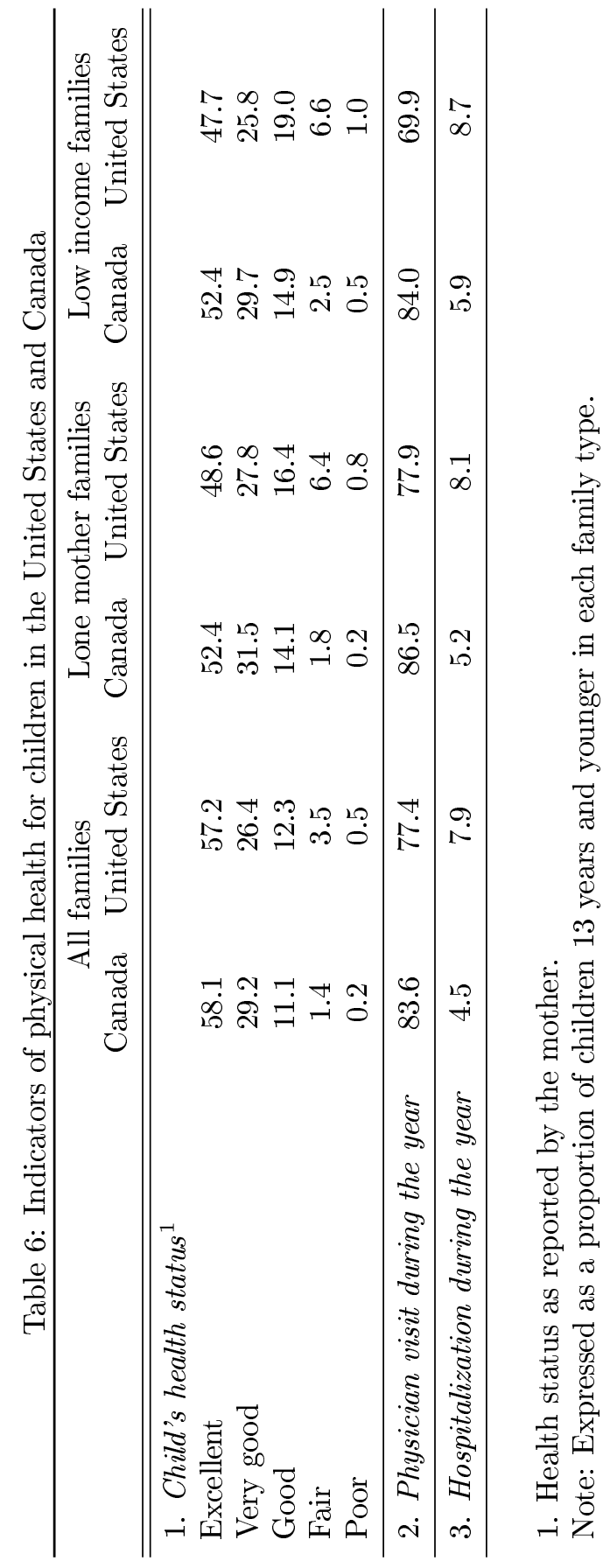


from lone mother families visit a dentist, compared - as mentioned - to almost 80 percent for children regardless of family type. In addition, there are no significant differences in these rates across the two countries.

American children have higher rates of hospitalization. About 4.5 percent of Canadian children versus 8 percent of American children are hospitalized during the year, a fact that may seem surprising given that a higher proportion of children are seen by physicians in Canada. It may be that visits to physicians act as an avoidance measure against some hospitalizations, or that the relatively poorer health of children in the United States leads to higher rates of hospitalization. As with doctor visits, patterns of hospitalization for different family types are relatively similar within each of the two countries. However, the children of low income parents are slightly more likely to experience a hospitalization than are other children. In Canada 5.9 percent stay overnight in hospital versus 4.5 percent of all children; in the United States 8.7 percent of low income children in comparison with 7.9 percent of all children are hospitalized during the year. The between-country differences are significant for all groups. ${ }^{30}$

Mental and physical health are important in their own right, but also because they may influence cognitive and learning outcomes. In fact, early learning and vocabulary development also varies significantly across the countries, with 4 and 5 year old Canadian children scoring significantly higher on a comparable test of school readiness. Canadian four year-olds have an average raw score on the Peabody Picture Vocabulary Test that is 10.3 percent above that of four year-old children in the United States. The gap for five year-olds is smaller at 6.2 percent, but still favours Canadian children. ${ }^{31}$

Mothers in the two countries report that similar proportions of children between the ages of 6 and 13 are doing well at school, although those in Canada report that a slightly higher proportion of children are doing very well (44 percent versus 38 percent). Mothers in the United States report a higher percentage of children with average performance: 28 percent versus 23 percent in Canada. As with mothers' assessments of health, the most notable difference between Canadian children and American children is at the bottom of the scale. The proportion of children performing below the middle or near the bottom in school is twice in the United States what it is in Canada ( 7 percent versus 3.4 percent). The schooling results for lone mother or low income children are not quite as good as for other children in both countries, although the same basic patterns in reports from mothers arise for them. Specifically, 5.8 percent of the children

\footnotetext{
${ }^{30}$ Children in the United States are also more likely to visit a mental health professional than are children in Canada. Approximately 6 percent of American children and 4 percent Canadian visit a mental health professional during the year, with American children also making a greater average number of visits. Recall that Canadian children are reported to be happier than are American children, although there are no significant differences between the two countries with respect to nervousness and tension or difficulty concentrating.

${ }^{31}$ During the Peabody Picture Vocabulary Test (PPVT) children are shown a set of pictures and asked to identify the one matching the word spoken to them. Their raw scores count the number of correct responses given. This test is regarded as a good measure of 'school readiness' and correlates well with future success at school as well as having the possible advantage that it is not a subjective assessment provided by the parent.
} 
of lone mothers are performing poorly in school in Canada in comparison with 10.7 percent in the United States. The difference for low income children is not as stark but is still significant between the two countries, with 5.3 percent in Canada and 8.3 percent in the United States performing poorly or very poorly in school.

Granted these indicators lack a certain objectivity. After all in both countries well over two-thirds of the children are reported by their mothers to be doing better than average in school. While this result is not unique to these data or this study, it is the differences between the two countries that are important. Furthermore, these differences hold up in more comprehensive tests of older children. For example, The International Mathematics and Science Study (TIMSS) offers information on how children aged 12 and 13 years compare across countries on standardized math and science tests. According to these results Canadian children perform substantially better on average in mathematics and somewhat better in science than do children in the United States. Both Canadian and American children are above the international mean for the math and science test scores. For the United States the standardized mean math score is 501.6 while for Canada is about $1 / 3$ of a standard deviation higher at 530.8 . The Canadian standardized mean score for science is slightly higher at 533.1, but the American science score is also higher than its math score at 514.9. According to these measures, Canadian children are doing substantially better in math and somewhat better in science than American children. ${ }^{32}$

Along most of these dimensions - mental and physical health, early learning, and academic performance in primary school - Canadian children, but particularly Canadian children from lone-parent or low income families have on average better outcomes than their American counterparts. As such this picture lines up with the differences in resources available to these children through family, markets, and public policy, and this would lead us to suggest that the foundation for economic mobility is already being laid in the years before these children become teenagers and make decisions concerning higher education and occupation of employment. As such it is very likely that the differences in the degree of generational mobility documented for young adults who came of age during the 1990s will continue at least for another generation of young adults.

\section{Conclusions}

In the United States there is a long social science tradition recognizing the value of a federal structure in developing effective public policies. Significant variations in public programs across States offers opportunities for learning about what works and what doesn't, and hence for the refinement of policy goals and improvements in program implementation. Our comparative study of the relationship between family economic background and adult outcomes in the United States and Canada is offered in this spirit, by extending the scope of the comparison across countries it offers another dimension for understanding

${ }^{32}$ See the TIMSS website at http://ustimss.msu.edu for more information. 
the nature of social goals, and how different institutional contexts play out in attaining them.

There are important similarities and differences between these two countries. The starting point for our analysis is the difference in outcomes that has been observed in the empirical economics literature dealing with economic mobility across the generations. International comparisons of the average degree of generational earnings mobility suggest that Canada is more mobile than the United States, but a closer look at studies that use particularly high quality data that are directly comparable across this pair of countries suggests that the difference is even larger than implied by the broad international literature. On average Canada is up to three times more mobile than the United States. Or another way of putting it, up to three times as much inequality is passed across the generations in the United States than in Canada. Furthermore, these differences arise from differences in the extremes of the earnings distribution: there is notably less mobility at the very top and the very bottom of the American income ladder. For this reason we focus our more detailed comparative analysis not just on the average child but also on the relatively disadvantaged, and try to chart the prospects for upward mobility in these two countries.

These cross-country differences in outcomes are not a reflection of different societal preferences, or interpretations of the meaning of equality of opportunity. In fact, it is valuable to compare these two particular relatively rich countries because they are so much alike. This similarity in public attitudes is confirmed in the comparative public opinion polls conducted and reported upon. Both countries value the ideal of equality of opportunity, and both define it in terms of individual freedoms but also individual responsibilities. Americans, however, are more inclined to view government as doing more to hinder than help this process. Yet, at the same time the citizens of both countries recognize the need for public policy to contribute to reaching this ideal, with Americans believing more than Canadians that a whole host of interventions would be effective in improving the prospects for economic mobility. One interpretation of these findings - an interpretation that only becomes evident a comparative contextis that in some sense this need is going unmet in the United States.

This is reflected in the actual resources available to children. We offer a descriptive overview of these resources organized loosely around a model of intergenerational economic mobility that highlights the role of families, labour markets, and public policies as together determining the degree of mobility and explaining differences between jurisdictions. The family context in which children are raised in the United States is more challenging than in Canada, raising the risks that some children will not see the full development of their capabilities. American labour markets are also more unequal raising the stakes for child outcomes, both elevating opportunities and heightening risks. Finally, public policy is less "progressive," not compensating in the same degree for family background and labour market inequality.

The portrait we paint of young children across these three dimensions underscores the fact that childhood outcomes differ for children before they reach their teen years, and potentially set them down pathways that will lead to dif- 
ferent adult outcomes. Mental and physical health, school readiness, and some education outcomes are all more developed in Canada. But this portrait also highlights some particularly relevant institutional differences in public policy between the countries that merit closer attention as the underlying causes.

The first concerns health care. The universal provision of accessible health care in Canada plays a role in the preventative care of children, reducing the number and severity of health shocks that could potentially lead to more severe difficulties. But in both countries issues of access are also more subtle, associated with economic and social barriers limiting visits to health care providers, ability to pay for prescriptions, and knowledge as to how to navigate the health care system. The anecdotal evidence provided by Scott (2005) with respect to the ability of adults to access and respond to care providers in the United States probably rings true for children on both sides of the border.

The second concerns the flexibility that parents have in making child care choices and deciding upon hours of work. The two countries have very different policies that offer different opportunities for parents in balancing the demands of family and workplace, particularly in the early years of a child's life. Canadian mothers and fathers would appear to have more flexibility as a result of significant policy changes in the mid 1990s that extended paid leave during the year after a child's birth as well as the legislative right to return to their jobs. There seems also to be more use of part-time employment. In the United States the limited nature of parental leave leads to a polarization in family decisions, with relatively well-off families able to either afford private child care or to have the mother withdraw from the labour market, while at the other extreme lone mothers have fewer options and are much more likely to continue working. This discussion leaves aside important issues of the quality of the care arrangements, an area of continued research.

The third deals with labour market inequalities and the role of tax-transfer programs. Left to their own, labour markets lead to roughly the same level of income poverty in these two countries, though there is more affluence on average in the United States and greater inequality. While the average Canadian child is not as affluent as the average American, the poorest Canadian is not as poor in an absolute sense as Americans at the bottom of the income distribution. Public income transfers play a much more important role in reducing poverty among Canadian children with virtually all families receiving some measure of public support. This is likely the result of the Canadian Child Tax Benefit, a progressive system of income transfers delivered through the income tax system with the generosity of the benefit varying with family market income and number of children. While this program has played a limited role in reducing the incidence of low income, it has significantly reduced the severity of poverty. This design contrasts with the Employment Income Tax Benefit in the United States, which is tied to employment. All this said our analysis has not accounted for the role of in-kind transfers in the United States, nor analysed the relative merits of targeted in-kind support versus broad-based money transfers. These alternative delivery mechanisms need to be evaluated not only in terms of the level of support they offer, but once again with respect to more subtle issues of 
access, stigma, and take-up rates.

Finally, our analysis highlights but leaves unaddressed important details concerning the quality and the variation in quality of public schooling. As suggested the financing of public education is very different across these countries. Education is a provincial responsibility in Canada, much in the way that the States have primary responsibility in the United States. But the financial resources available to schools are not linked to local property taxes, being tied rather to the province-wide income tax. This permits a more equal allocation of resources across municipalities and neighbourhoods than the United States, and may contribute to a higher overall level of quality that is ultimately reflected in the higher test score outcomes we document for Canadian children just before their entry to high school.

It is important to re-emphasize that much of our analysis refers to a particular cohort of young people, those who were young teens at the turn of the century and who will soon be coming of age as adults. Demographics, labour markets, and public policy have all changed significantly over the course of the last decade. These changes may have a bearing on how younger cohorts of children will fare as adults. But given the configuration of these forces during the period relevant for the cohort we study, essentially the 1990s and early 2000 s, our analysis suggests that the next wave of intergenerational mobility studies - which will be based on this very group - will likely find that the degree of mobility continues to remain greater in Canada than in the United States.

All this said, to some measure the observation that Alesina and Glaeser (2004) make in beginning their explanation for the much smaller size of the welfare state in the United States compared to Europe also holds when the comparison is made to Canada: "If one were born (and remained) at the bottom end of the income distribution, one would be much better taken care of by government policies in Europe than by those in the the United States." (Alesina and Glaeser 2004, page 2.) But their explanation for different levels of government support is not so easily transposed to the Canadian context. "American institutions [they argue] have strengthened the political right and given antiredistribution politicians the ability to push their world view - and this world view emphasizes economic opportunity. European institutions, to the contrary, have empowered the left; as a result, leftist leaders have been able to indoctrinate Europeans with Marxist ideals about class solidarity and the capriciousness of the capitalist system." (page 12.)

This sharp dichotomy between values and institutions that pit equality of opportunity against equality of outcomes does not resonate in a comparison involving the United States and Canada. Our analysis has shown that Canadians value equality of opportunity no more and no less than Americans, and they have as much aversion for equality of outcomes. But Canadians have drawn the balance between family and labour markets differently than Americans-using in a pragmatic way the instruments available through public policy — and for this reason the tie between family background and the adult outcomes of children will likely to continue to be looser in Canada for at least another generation. 


\section{References}

[1] Aaronson, Daniel and Bhashkar Mazumder (2008). "Intergenerational Economic Mobility in the United States, 1940 to 2000." Journal of Human Resources. Vol. 43, pages 139-172.

[2] Aydemir, Abdurrahman, Wen-Hao Chen, and Miles Corak (2009)."Intergenerational Earnings Mobility among the Children of Canadian Immigrants." Review of Economics and Statistics. Vol. 91, pages 377-97.

[3] Alesina, Alberto and Edward L. Glaeser (2004). Fighting Poverty in the US and Europe: A World of Difference. Oxford: Oxford University Press.

[4] Baker, Michael, Jonathan Gruber, and Kevin Milligan (2008). "Universal Childcare, Maternal Labor Supply, and Family Wellbeing." Journal of Political Economy. Vol. 116, pages 709-745.

[5] Becker, Gary S. and Nigel Tomes (1979). "An Equilibrium Theory of the Distribution of Income and Intergenerational Mobility." Journal of Political Economy. Vol. 87, pages 1153-89.

[6] Behrman, Jere R. and Mark R. Rosenzweig (2002). "Does Increasing Women's Schooling Raise the Schooling of the Next Generation?" American Economic Review. Vol. 92, No. 1, pp. 323-34.

[7] Blum Munroe, H., M. Boyle, and D. Offord (1988). "Single parent families: child psychiatric disorder and school performance." Journal of the American Academy of Child and Adolescent Psychiatry. Vol. 27, pages 214-19.

[8] Burton, Peter, Shelley Phipps, and Lori Curtis (2002). "All in the Family: A Simultaneous Model of Parenting Style and Child Conduct." American Economic Review. Vol. 92, pages 368-72.

[9] Bushnik, Tracey (2006). Child care in Canada. Ottawa: Statistics Canada, Catalogue Number 89-599-MIE-No 3.

[10] Cadman, David, Peter Rosenbaum, Michael Boyle, and David R. Offord (1991). "Children with Chronic Illness: Family and Parent Demographic Characteristics and Psycho-social Adjustment." Pediatrics. Vol. 87, pages 884-9.

[11] Card, Davd, John DiNardo and Eugena Estes (2000). "The More Things Change, Immigrants and the Children of Immigrants in the 1940s, the 1970s, and the 1990s." In G. Borjas (editor), Issues in the Economics of Immigration. Chicago: NBER and University of Chicago Press.

[12] Card, David and Richard B. Freeman, editors (1993). Small Differences that Matter: Labor Markets and Income Maintenance in Canada and the United States. Chicago: University of Chicago Press and National Bureau of Economic Research. 
[13] Case, Anne, Darren Lubotsky, and Christina Paxson (2002). "Economic Status and Health in Childhood: The Origins of the Gradient." American Economic Review. Vol. 92, page 1308-34.

[14] Case, Anne and Christina Paxson (2001). "Mothers and Others: Who Invests in Children's Health?" Journal of Health Economics. Vol. 20, pages $301-28$.

[15] Cervini, Maria (2009). "Intergenertional earnings mobility in Spain." Paper presented to the Annual Meeting of the European Society for Population Economics, Seville Spain.

[16] Coleman, James S. (1988). "Social Capital in the creation of Human Capital." American Journal of Sociology. Vol. 94, Supplement, S95-S120.

[17] Corak, Miles (2010). Chasing the Same Dream, Climbing Different Ladders: Economic Mobility in the United States and Canada. Washington DC: Economic Mobility Project, The Pew Charitable Trust.

[18] Corak, Miles (2006). "Do Poor Children Become Poor Adults? Lessons for Public Policy from a Cross Country Comparison of Generational Earnings Mobility." In John Creedy and Guyonne Kalb (editors). Research on Economic Inequality. Vol. 13, Dynamics of Inequality. The Netherlands: Elsevier Press.

[19] Corak, Miles (2001). "Death and Divorce: The Long-Term Consequences of Parental Loss on Adolescents." Journal of Labor Economics. Vol. 19, pages 682-715.

[20] Corak, Miles and Andrew Heisz (1999). "The Intergenerational Earnings and Income Mobility of Canadian Men: Evidence from Longitudinal Income Tax Data." Journal of Human Resources. Vol. 34, pages 504-33.

[21] Currie, Janet and Mark Stabile (2003). "Socioeconomic Status and Child Health: Why is the Relationship Stronger for Older Children?" American Economic Review. Vol. 93, pages 1813-23.

[22] Dooley, Martin, Lori Curtis, Ellen Lipman and David Feeney (1998). "Child Behaviour, Poor School Performance and Social Problems." In Miles Corak (editor). Labour Markets, Social Institutions, and the Future of Canada's Children. Ottawa: Statistics Canada, Catalogue No. 89-553.

[23] Economic Mobility Project (2009). Findings from a National Survey \& Focus Groups on Economic Mobility. Washington: Pew Charitable Trusts. Report dated March 12th. Available at http://www.economicmobility.org/poll2009, accessed October 2009.

[24] Esping-Andersen, Gøsta (1990). The Three Worlds of Welfare Capitalism. Princeton: Princeton University Press. 
[25] Fortin, Nicole M. and Sophie Lefebvre (1998). "Intergenerational Income Mobility in Canada." In Miles Corak (editor). Labour Markets, Social Institutions, and the Future of Canada's Children. Ottawa: Statistics Canada, Catalogue No. 89-553.

[26] Furchtgott-Roth, Diana, Louis Jacobson and Christine Mokher (2009). Strengthening Community Colleges' influence on Economic Mobility. Washington: Economic Mobility Project, Pew Charitable Trusts.

[27] Grawe, Nathan D. (2006). "The Extent of Lifecycle Bias in Estimates of Intergenerational Earnings Persistence." Labour Economics. Volume 13, pages $551-70$.

[28] Grawe, Nathan D. (2004). "Intergenerational Mobility for Whom? The Experience of High and Low Earnings Sons in International Perspective." In Miles Corak (editor). Generational Income Mobility in North America and Europe. Cambridge: Cambridge University Press.

[29] Haider, Steven and Gary Solon (2006). "Life-cycle variation in the association between current and lifetime earnings." American Economic Review. Vol. 96, pages 1308-20.

[30] Haskins, Ron and Isabel Sawhill (2009). Creating an Opportunity Society. Washington: Brookings Institution Press.

[31] Hertz, Tom (2004). "Rags, Riches and Race: The Intergenerational Economic Mobility of Black and White Families in the United States." In Samuel Bowles, Herbert Gintis, and Melissa Osborne (editors). Unequal Chances: Family Background and Economic Success. Princeton: Princeton University Press and Russell Sage.

[32] Holmlund, Helena, Mikael Lindahl, and Erik Plug (2008). "The Causal Effect of Parent's Schooling on Children's Schooling: A Comparison of Estimation Methods." IZA Discussion Paper Number 3630.

[33] Jantti, Markus, Knut Roed, Robin Naylor, Anders Bjorklund, Brent Bratsberg, Oddbjorn Raaum, Eva Osterbacka, Tor Ericksson (2006). "American Exceptionalism in a New Light: A Comparison of Intergenerational Earnings Mobility in the Nordic Countries, the United Kingdom, and the United States." IZA Discussion Paper No. 1938.

[34] Jencks, Christopher and Laura Tach (2006). "Would Equal Opportunity Mean More Mobility?" In Stephen L. Morgan, David B. Gursky and Gary S. Fields (editors). Mobility and Inequality. Stanford: Stanford University Press.

[35] Knudsen, Eric I., James J. Heckman, Judy L. Cameron, and Jack P. Shonkoff (2006). "Economic, neurobiological, and behavioural perspectives on building America's future workforce." Proceedings of the National Academy of Sciences. Vol. 103, No. 27 pp. 10155-10162. 
[36] Lang, Kevin and Jay L. Zagorsky (2001). "Does Growing Up with a Parent Absent Really Hurt?" Journal of Human Resources. Vol. 36, pages 253-273.

[37] Lee, Chul-In and Gary Solon (2009). "Trends in Intergenerational Income Mobility." Review of Economics and Statistics. Vol. 91, pages 766-72.

[38] Leigh, Andrew. 2007. "Intergenerational Mobility in Australia." The B.E. Journal of Economic Analysis \& Policy. Berkeley Electronic Press, vol. $7(2)$.

[39] Lipset, Seymour Martin (1950). Agrarian Socialism: The Cooperative Commonwealth Federation in Saskatchewan, a Study in Political Sociology. Berkeley: University of California Press.

[40] Mayer, Susan E. and Leonard M. Lopoo (2004). "What do Trends in the Intergenerational Economic Mobility of Sons and Daughters in the United States Mean?" In Miles Corak (editor). Generational Income Mobility in North America and Europe. Cambridge: Cambridge University Press.

[41] Mazumder, Bhashkar (2005). "Fortunate Sons: New Estimates of Intergenerational Mobility in the United States using Social Security Earnings Data." Review of Economics and Statistics. Vol. 87, pages 235-55.

[42] Mazumder, Bhashkar (2004). "The Apple Falls Even Closer to the Tree than We Thought: New and Revised Estimates of the Intergenerational Inheritance of Earnings." In Samuel Bowles, Herbert Gintis, and Melissa Osborne (editors). Unequal Chances: Family Background and Economic Success. Princeton: Princeton University Press and Russell Sage.

[43] Mulligan, Casey B. (1997). Parental Priorities and Economic Inequality. Chicago: University of Chicago Press.

[44] New York Times Correspondents (2005). Class Matters. New York: Times Books, Heny Holt and Company.

[45] OECD (2009). OECD Factbook 2009. Available at http://dx.doi.org/10.1787/540641728538.

[46] OECD (2008). Growing unequal? Income Distribution and Poverty in OECD Countries. Paris: Organization for Economic Cooperation and Development.

[47] Oreopoulos, Philip, Mark Stabile, Randy Walld, and Leslie L. Roos (2008). "Short-, Medium-, and Long-Term Consequences of Poor Infant Health: An Analysis Using Siblings and Twins." Journal of Human Resources. Vol. 43 , page $88-138$.

[48] Phipps, Shelley (2002). "The Well-Being of Young Canadian Children in International Perspective: A Functionings Approach" The Review of Income and Wealth. Series 48(4), pages 51-73. 
[49] Piraino, Patrizio. 2007. "Comparable Estimates of Intergenerational Income Mobility in Italy." The B.E. Journal of Economic Analysis 83 Policy. Berkeley Electronic Press, vol. 7(2).

[50] Reville, Robert T. (1995). "Intertemporal and Life Cycle Variation in Measured Intergenerational Earnings Mobility." RAND Working Paper.

[51] Roemer, John E. (2004). "Equal Opportunity and Intergenerational Mobility: Going Beyond Intergenerational Income Transition Matrices." In Miles Corak (editor). Generational Income Mobility in North America and Europe. Cambridge: Cambridge University Press.

[52] Sawhill, Isabel V. and John E. Morton (2008). Economic Mobility: Is the American Dream Alive and Well? Washington: Economic Mobility Project, Pew Charitable Trusts.

[53] Scott, Janny (2005). "Life at the top in America isn't just better, it's longer." In New York Times Correspondents. Class Matters. New York: Times Books, Heny Holt and Company.

[54] Smith, James P. (2009). "The Impact of Childhood Health on Adult Labor Market Outcomes." Review of Economics and Statistics. Vol. 91, pages 478489.

[55] Solon, Gary (2004). "A Model of Intergenerational Mobility Variation over Time and Place.'In Miles Corak (editor). Generational Income Mobility in North America and Europe. Cambridge: Cambridge University Press.

[56] Solon, Gary (2002). "Cross-Country Differences in Intergenerational Earnings Mobility." Journal of Economic Perspectives. Vol. 16, pages 59-66.

[57] Solon, Gary (1999). "Intergenerational Mobility in the Labor Market." In Orley C. Ashenfelter and David Card (editors). Handbook of Labor Economics, Volume 3A. Amsterdam: Elsevier Science.

[58] Solon, Gary (1992). "Intergenerational Income Mobility in the United States." American Economic Review. Vol. 82, pages 393-408.

[59] UNICEF (2001). A League table of teenage births in rich nations. Report Card No. 3, July 2001. UNICEF: Innocenti Research Centre, Florence.

[60] Wessel, David (2005). "As Rich-Poor Gap Widens in the U.S., Class Mobility Stalls." Wall Street Journal. May 13, page 1.

[61] Zimmerman, David J. (1992). "Regression Toward Mediocrity in Economic Structure." American Economic Review. Vol. 82, pages 409-29. 